\title{
Blending Human and Artificial Intelligence to Support Autistic Children's Social Communication Skills
}

\author{
KAŚKA PORAYSKA-POMSTA, ALYSSA M. ALCORN, and KATERINA AVRAMIDES, \\ UCL Institute of Education \\ SANDRA BEALE, Birkbeck, University of London \\ SARA BERNARDINI, Royal Holloway \\ MARY ELLEN FOSTER, University of Glasgow \\ CHRISTOPHER FRAUENBERGER, HCI Group \\ JUDITH GOOD, University of Sussex \\ KAREN GULDBERG, University of Birmingham \\ WENDY KEAY-BRIGHT, Cardiff School of Art and Design \\ LILA KOSSYVAKI, University of Birmingham \\ OLIVER LEMON, Heriot-Watt University \\ MARILENA MADEMTZI, Yale University \\ RACHEL MENZIES, University of Dundee \\ HELEN PAIN, University of Edinburgh \\ GNANATHUSHARAN RAJENDRAN, Heriot-Watt University \\ ANNALU WALLER, University of Dundee
}

\begin{abstract}
This research was funded by the ESRC and EPSRC under TLRP-TEL programme (Grant number RES-139-25-0395-A). Authors' addresses: K. Porayska-Pomsta and K. Avramides, University College London, UCL Institute of Education, UCL Knowledge Lab, 23-29 Emerald Street, London WC1N 3QS, United Kingdom; emails: K.Porayska-Pomsta@ucl.ac.uk, k.avramides@ioe.ac.uk; A. Alcorn, Centre for Research in Autism and Education, UCL Institute of Education, University College London, 55-59 Gordon Square, London, WC1H 0NU, United Kingdom; email: a.alcorn@ucl.ac.uk; S. Beale and T. J. Smith, Department of Psychological Sciences, Birkbeck, University of London, Malet Street, London, WC1E 7HX, United Kingdom; emails: Sara.Bernardini@rhul.ac.uk, tj.smith@bbk.ac.uk; S. Bernardini, Department of Computer Science, Royal Holloway, University of London, Egham, TW20 0EX, United Kingdom; email: Sara.Bernardini@rhul.ac.uk; M. E. Foster, School of Computing Science, 18 Lilybank Gardens, Glasgow, Scotland, United Kingdom; email: MaryEllen.Foster@glasgow.ac.uk; C. Frauenberger, HCI Group, Institute of Visual Computing and Human-Centered Technology, TU Wien, Argentinierstrasse 8, 1040 Vienna, Austria; email: christopher.frauenberger@tuwien.ac.at; J. Good, University of Sussex, Sussex House, Falmer, Brighton, BN1 9RH, United Kingdom; email: J.Good@sussex.ac.uk; K. Guldberg and L. Kossyvaki, School of Education, University of Birmingham, Birmingham B152TT, United Kingdom; email: K.K.Guldberg@bham.ac.uk; W. Keay-Bright, Cardiff School of Art and Design, Cardiff Metropolitan University, Western Avenue, Llandaff, Cardiff, CF5 2YB, United Kingdom; email: wkbright@cardiffmet.ac.uk; O. Lemon, Department of Mathematical and Computer Sciences, Earl Mountbatten Building, Heriot-Watt University, United Kingdom; email: o.lemon@hw.ac.uk; M. Mademtzi, Yale University, Child Study Center, 230 South Frontage Road, New Haven, CT, 06519, United States; email: marilena.mademtzi@yale.edu; R. Menzies and A. Waller, Computing School of Science and Engineering, University of Dundee, Dundee DD1 4HN, Scotland, United Kingdom; emails: \{r.menzies, a.waller\}@dundee.ac.uk; H. Pain, School of Informatics, 10 Crichton Street, Edinburgh EH8 9AB, United Kingdom; email: helen@inf.ed.ac.uk; G. Rajendran, Department of Psychology, School of Social Sciences, Heriot-Watt University, Edinburgh EH14 4AS, Scotland, United Kingdom; email: t.rajendran@hw.ac.uk; S. Wass, University of East London, Water Lane, London E15 4LZ, United Kingdom; email: s.v.wass@uel.ac.uk.
\end{abstract}

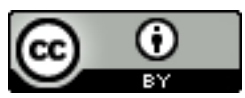

This work is licensed under a Creative Commons Attribution International 4.0 License.

(C) 2018 Copyright held by the owner/author(s).

1073-0516/2018/12-ART35 \$15.00

https://doi.org/10.1145/3271484 
SAM WASS, University of East London

TIM J. SMITH, Birkbeck, University of London

This article examines the educational efficacy of a learning environment in which children diagnosed with Autism Spectrum Conditions (ASC) engage in social interactions with an artificially intelligent (AI) virtual agent and where a human practitioner acts in support of the interactions. A multi-site intervention study in schools across the UK was conducted with 29 children with ASC and learning difficulties, aged 4-14 years old. For reasons related to data completeness and amount of exposure to the AI environment, data for 15 children was included in the analysis. The analysis revealed a significant increase in the proportion of social responses made by ASC children to human practitioners. The number of initiations made to human practitioners and to the virtual agent by the ASC children also increased numerically over the course of the sessions. However, due to large individual differences within the ASC group, this did not reach significance. Although no evidence of transfer to the real-world post-test was shown, anecdotal evidence of classroom transfer was reported. The work presented in this article offers an important contribution to the growing body of research in the context of AI technology design and use for autism intervention in real school contexts. Specifically, the work highlights key methodological challenges and opportunities in this area by leveraging interdisciplinary insights in a way that (i) bridges between educational interventions and intelligent technology design practices, (ii) considers the design of technology as well as the design of its use (context and procedures) on par with one another, and (iii) includes design contributions from different stakeholders, including children with and without ASC diagnosis, educational practitioners, and researchers.

\section{CCS Concepts: • Human-centered computing $\rightarrow$ Field studies; Social and professional topics $\rightarrow$ Children;}

Additional Key Words and Phrases: Autism, artificially intelligent agent, social communication, intelligent learning environments, neurodiversity

\section{ACM Reference format:}

Kaśka Porayska-Pomsta, Alyssa M. Alcorn, Katerina Avramides, Sandra Beale, Sara Bernardini, Mary Ellen Foster, Christopher Frauenberger, Judith Good, Karen Guldberg, Wendy Keay-Bright, Lila Kossyvaki, Oliver Lemon, Marilena Mademtzi, Rachel Menzies, Helen Pain, Gnanathusharan Rajendran, Annalu Waller, Sam Wass, and Tim J. Smith. 2018. Blending Human and Artificial Intelligence to Support Autistic Children's Social Communication Skills. ACM Trans. Comput.-Hum. Interact. 25, 6, Article 35 (December 2018), 35 pages. https://doi.org/10.1145/3271484

\section{INTRODUCTION}

Autism is a spectrum of neuro-developmental disorders that affects the way in which a person communicates with and relates to other people, as well as how they make sense of the world around them (NAS 2016). The main areas of difficulty in Autism Spectrum Conditions (ASC) are as follows: (i) social communication and interaction, involving problems with both verbal and nonverbal language, e.g., difficulty with initiating or responding to bids for interaction, or with taking turns in conversations and (ii) restricted, repetitive patterns of behaviour, interests, or activities, for example, difficulties with adapting to novel environments or coping with unexpected change (see (APA 2013) for a comprehensive list of potential difficulties). The degree to which such difficulties are present and their exact nature varies between individuals and possibly across cultural and situational contexts. This heterogeneity necessitates individualised and adaptive support regimes that are sensitive to the individuals' real-life routines and that are not confined to laboratory or clinical intervention settings.

A wide range of clinical and non-clinical interventions exists that aim to facilitate the learning and development of social communication skills. Over the past decade, technology-enhanced 
methods have attracted increasing attention in both the autism and educational communities for their potential to impact both research and practice (Goodwin 2008; Parsons et al. 2015; Parsons and Mitchell 2017). Software interventions have targeted language skills, e.g., (Anwar et al. 2011; Bosseler and Massaro 2003; Massaro 2006; Rahman et al. 2011), affective skills, e.g., (Abirached et al. 2009; Beaumont and Sofronoff 2008; Finkelstein et al. 2009; Hopkins et al. 2011; Schuller et al. 2013), and social interaction skills, e.g., (Barakova et al. 2007; Battocchi et al. 2013; Dautenhahn and Werry 2004; Kandalaft et al. 2013; Kozima et al. 2009). The latter include approaches to fostering social initiation in peer-to-peer collaborative contexts (Malinverni et al. 2014; Mora-Guiard et al. 2016; Tartaro and Cassell 2008), attentional control (Bartoli et al. 2013), and imaginary/symbolic play (Herrera et al. 2008, 2012) through exploratory full body interaction environments. The existing interventions examine the design and use of both advanced Artificial Intelligence (AI), e.g., as in Barakova et al. (2007) social robotics work, as well as technologically shallower interactive interface designs, e.g., as in Herrera et al. (2008, 2012) approach to full-body interactions.

The proliferation of different technologies and their applications for autism is being increasingly accompanied by a body of evidence suggesting that technology, in the broad sense of the word and in tightly controlled environments, may provide effective support for this target group (Cobb 2007; Parsons et al. 2007; Parsons and Mitchell 2017). This is especially true in relation to within technology use improvements, e.g., (Wass and Porayska-Pomsta 2014), with some indication of the potential for generalisation to real-world situations (Bosseler and Massaro 2003; FletcherWatson 2014; Golan et al. 2010; Grynszpan et al. 2014; Hourcade et al. 2013; Pennington 2010; Ramdoss et al. 2011a, 2011b; Tartaro and Cassell 2008). Coupled with this emerging evidence is a growing demand from diverse groups, including parents, educators, and individuals with ASC, for the adoption of an inclusive support model that views autism as a difference in abilities rather than as a spectrum of deficits. In such an inclusive model, first, any intervention should be adapted to individuals' strengths rather than their deficits, with the therapeutic regimes being personalised to their individual needs. Second, appropriate adjustments should be made not only to the individuals' physical, but also transactional environments to facilitate and scaffold their engagement in social and interpersonal interactions (Prizant et al. 2003). The focus on strengths rather than deficits, and the importance of adaptable and adaptive environments to the success of interventions, has been long highlighted as key to best educational practice (Biesta 2007; Dewey 1998). This view also aligns with the aspirations of Artificial Intelligence in Education research, where moment-by-moment adaptation to the idiosyncratic needs and actions of learners is of central interest, e.g., (Woolf 2008). This, together with AI's long-term key ambition to emulate human behaviours in socially credible ways, provides a strong motivation for examining the educational and interactional potential of AI technologies in this context.

Given that initiations and responses that are either absent or inappropriate are seen as key areas of difficulty in ASC (APA 2013), this article focuses on these two behaviours. Children with ASC tend to initiate all types of communication infrequently compared with typically developing (TD) or developmentally delayed peers (Mundy et al. 2003), and respond to partners in restricted or self-serving ways. A key aim of the work presented here was to create an environment in which the child was encouraged and motivated to produce spontaneous communication behaviours, i.e., to engage in 'communication in the absence of [a] defined antecedent' (Chiang and Carter 2008). Such behaviours are treasured by parents and practitioners, because they occur infrequently and when they do, they indicate that the child acknowledges them as social agents.

This article presents the design and evaluation of a technology called ECHOES, which opportunistically blends human and AI support for autistic children, aged 4-14 years old, ${ }^{1}$ in their

${ }^{1}$ The ECHOES environment was originally designed for children aged 4-7 years old. However, as explained in Section 4, several of the study participants were chronologically older, but developmentally within or below the target age range. 
exploration of social interaction skills. Such blending aims to deliver rich and flexible transactional support to children as advocated in the autism best practices. Here, AI serves as a stepping stone for the social interactions with the humans, whereby human practitioners provide on-demand support when a child is willing and able to interact and communicate with them, or where a combination of technology and human intelligence is necessary to cater adequately for the interaction needs of the specific child.

The contributions of the work presented are four-fold. First, the study provides a detailed example of how human-computer interaction can be orchestrated in a way that blends human and artificial intelligence for the benefit of each individual child. This is a particularly timely contribution, given the emerging evidence-driven trend in AI in Education of adopting carefully blended AI-human approaches for supporting learning (Baker 2016). Second, through the examination of the efficacy of the ECHOES approach, the study spotlights the potential of technology as a trigger and a catalyst for meaningful social communication between ASC children and adults in nonclinical contexts such as schools. Third, in contrast with much research in technology-enhanced approaches to autism intervention, the work extends existing research by targeting children at the lower end of the ASC. Fourth, the research presented highlights important methodological challenges related to the ways in which any improvements in autistic children's social communication may be measured meaningfully in a way that (i) informs and innovates front-line practices, (ii) points to how educational interventions for this population may be designed and delivered specifically with the help of AI technologies, and (iii) informs how the definition of optimal outcome for children with ASC may need to be framed to allow for the design and delivery of more inclusive support regimes than are currently routinely available (for further discussion see Sections 4 and 7.4).

The rest of the article is organised as follows. Section 2 describes the ECHOES environment, explaining its pedagogical underpinnings. Section 3 describes the design and functionality of the ECHOES AI agent. Section 4 introduces the study design along with the research questions addressed. Section 5 presents the ECHOES data annotation scheme, while Section 6 provides the results of the study. Section 7 discusses the results by exploring their broader implications to technology-enhanced interventions for autism, and by outlining key methodological considerations related to enabling inclusive interventions and technological designs in this context. The concluding remarks are given in Section 8 together with examples of work that has already emerged from the ECHOES project, illustrating the rich interdisciplinary basis that the work presented here offers for future work more generally. Supplementary materials related to the ECHOES system architecture and detailed examples of the ECHOES learning activities are provided in Appendix (A).

\section{THE DESIGN OF THE ECHOES ENVIRONMENT}

ECHOES is a single user technology-enhanced learning environment that utilises an artificially intelligent (AI) virtual character, ${ }^{2}$ called Andy, as a social partner for children with ASC and their TD peers, to help them learn and/or improve social communication skills (see Figure 1; for details of Andy's intelligence, see, e.g., (Bernardini and Porayska-Pomsta 2013)). The design of ECHOES was optimised to the following:

(1) Encourage and support behavioural change, through

(a) a child-centred approach;

(b) exploration and play opportunities;

(c) potential interaction with social partners (i.e., virtual or human partners), providing opportunities for the child to initiate and respond to social communication;

\footnotetext{
${ }^{2}$ The terms 'artificial agent' and 'virtual character' will be used interchangeably in this article.
} 


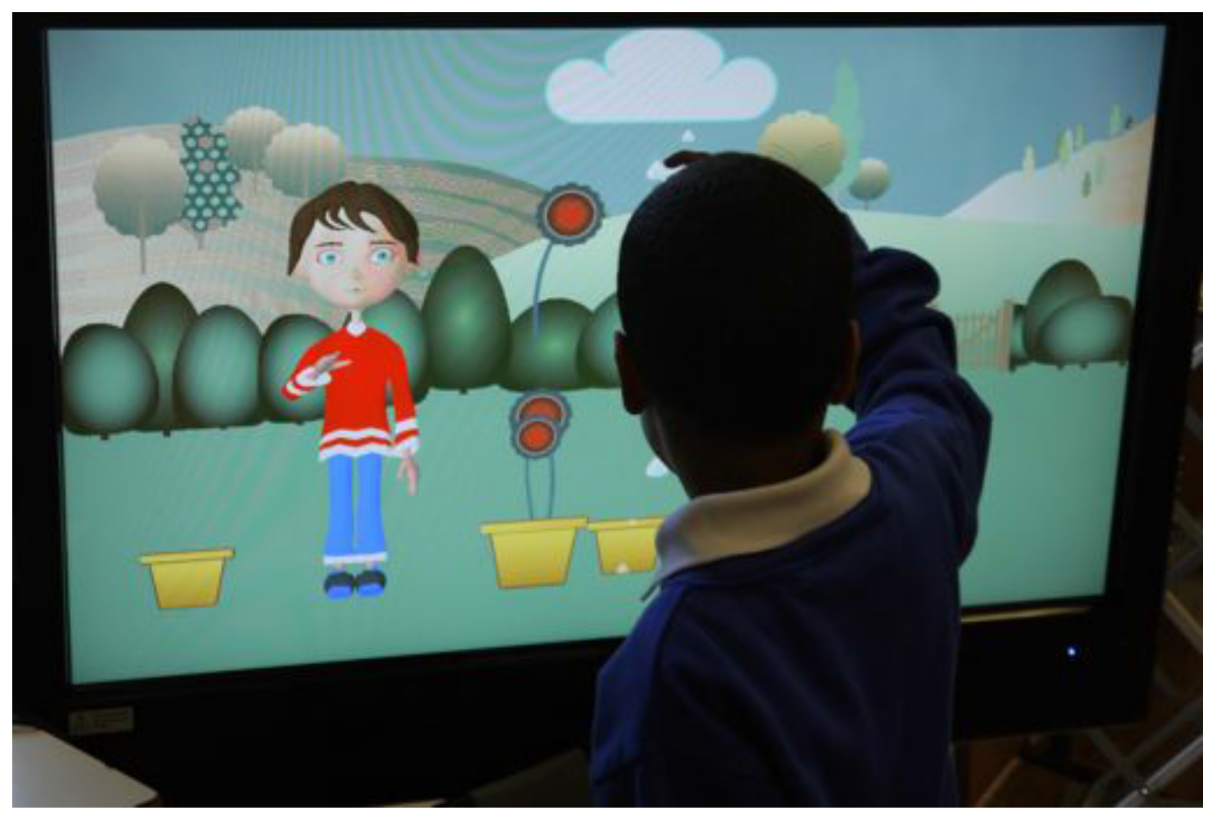

Fig. 1. A child playing with the interactive cloud through the ECHOES multi-touch display.

(2) Deliver learning activities based on existing evidence of best practice in autism - in this case the social communication, emotional regulation and transactional support (SCERTS) model (Prizant et al. 2006) (see Section 2.1 for details);

(3) Be informed by input from stakeholders, including children with and without autism, practitioners, and experts in developing technology for children with ASC;

(4) Be suitable for use by young children with ASC, who may also have learning difficulties ${ }^{3}$;

(5) Be suitable for use in school environments.

In ECHOES, children can both explore different situations involving the artificial agent and rehearse them repeatedly. The interaction between the child and the environment is facilitated through a large 42-in. multi-touch screen, which allows children to manipulate different interactive objects on the screen. The interactive objects provide the opportunities for shared attention and interaction between the agent and the child, and between the child and the human practitioner. The scale of the screen allows children to move freely in front of it. The touch interface caters for children's varying motor control capabilities, as well as for young children's low literacy. To reduce the complexity and potential difficulties of executing touch gestures such as those with a timing element (e.g., double tap or long touch) or those requiring multiple touch points (pinch), the input gestures are restricted to the simplest and least ambiguous possibilities (touch, drag, swipe up/down). From the outset, ECHOES was developed for use in schools and specialist units by children aged 4-7 years old, or of corresponding developmental age (in the studies presented, the chronological age was sometimes as old as 14 years).

\subsection{Pedagogical Underpinnings of ECHOES}

In designing ECHOES, we drew on best practices in autism intervention (Prizant et al. 2006) and consulted with stakeholders throughout, including teachers and other practitioners, children with

\footnotetext{
${ }^{3}$ This is often referred to as 'intellectual disability' outside of the UK.
} 
and without autism, researchers specialising in autism, and experts in technology design for children with ASC and other special needs. In doing so, we adopted a participatory design approach such that stakeholders could engage with the idea of ECHOES in a personally meaningful way, and express their views and ideas about the ways in which the technology might be shaped to accommodate their individual needs.

An early study (Alcorn et al. 2011) alerted us to the potential of ECHOES as an object for social communication: The presence of the researcher, and the children's spontaneous interaction with them, led to the explicit inclusion of the human partner in the interaction with the ECHOES environment, in addition to the AI agent. This blending of human and AI interaction provided two potential social partners for children while they interacted with ECHOES, offering them a richer, more robust and potentially more immediately transferrable experience than might be possible with only the AI agent as the social partner. The design requirements for ECHOES were based on the outputs of 14 participatory design workshops. Formative evaluation studies, involving children with and without a diagnosis of autism, were carried out using increasingly sophisticated prototypes of ECHOES. In total, over 80 children and more than 30 adults contributed to the ECHOES design process. For details of the individual workshops and their outcomes see (Bernardini et al. 2014; Frauenberger et al. 2013, 2010, 2011; Porayska-Pomsta et al. 2011).

The design of ECHOES was informed by and validated against the SCERTS model (Prizant et al. 2003) - A comprehensive approach to autism assessment and intervention, combining clinical as well as educational approaches. SCERTS addresses the core challenges related to ASC, and aims to support children in developing a number of key skills across the following three dimensions that are crucial to social interaction: (1) social communication (SC): spontaneous and functional communication, emotional expression, and secure and trusting relationships with others; (2) emotional regulation (ER): the ability to maintain a well-regulated emotional state to cope with everyday stress and to be available for learning and interacting; and (3) transactional support (TS): the development and implementation of support to help caregivers to respond to the child's needs and interests, to modify and adapt the environment, and to provide tools to enhance learning.

SCERTS breaks down these three domains into a number of further components and, for each one, provides a detailed description of the objectives to be achieved, the intervention strategies available to practitioners and parents, and the criteria for assessing the child's current skills and needs. In designing ECHOES and the learning activities therein, we built explicitly on this operationalisation of social communication. We also used the SCERTS assessment protocol as the basis for developing a bespoke annotation scheme, which we used to code the video data of the children's interactions with ECHOES. The SCERTS framework and the ECHOES' annotation scheme developed thereupon are presented in detail in Section 5.

\subsection{The ECHOES Learning Activities}

Children's interactions with ECHOES are structured around 12 learning activities that focus on social communication and, in particular, on the following: (1) joint attention: a child's ability to coordinate and share attention by looking towards people or shifting gaze between people and objects, share emotions by using facial expressions, express intentions, engage in turn-taking, and participate in reciprocal social interactions by initiating/responding to bids for interaction; and (2) symbolic use: a child's understanding of meaning expressed through conventional gestures, words, and sentences, and their ability to use non-verbal means and vocalisations to share intentions. The learning activities correspond directly to the intervention goals specified in the SCERTS framework.

One of SCERTS' principles is that in order to support joint attention, any activities performed with a child need to share 'an obvious unifying theme' (Prizant et al. 2003). Therefore, all ECHOES 
activities are set in a 'magic' garden inhabited by $\mathrm{Andy}^{4}$ - the AI agent. The ECHOES garden is magical, because it contains interactive objects that behave in unusual ways, sometimes transforming into other objects when touched by the agent or the child. For example, tapping a flower turns it into a floating bubble or a bouncy ball, depending on the type of touch-gesture used. The design of the environment, the objects and their behaviours, was informed by participatory design work conducted with children with ASC, TD children, parents, and practitioners, as described is Section 2.1. The idea behind the unusual/magical behaviours of the ECHOES objects was to create opportunities for sustained attentional interest and exploration, and for joint activities between the child, the agent and/or the human social partner.

In order to offer children a structured experience when interacting with ECHOES, whilst also leaving room for the children's own expression and discovery, we designed two sets of activities as follows: (i) closed-task activities, with a clear sequence of steps and a predetermined end-point; and (ii) exploratory activities, with no predetermined end-point and whose main objectives are social reciprocity, turn taking and mutual enjoyment. For example, sorting a set of balls by colour or collecting a predefined number of flowers are examples of closed-task activities that end once all of the objects are either sorted or collected. In contrast, taking turns with the agent to shake a virtual cloud that produces rain and causes flowers to grow, or throwing virtual bouncy balls through the cloud to make them change colour, represent exploratory activities that can go on for as long as the child wishes or is deemed productive by the accompanying practitioner (see Table 1 for a list of all ECHOES activities and the possible interactions between the child, the agent, and the human; see also Appendix A.2 for detailed examples).

Most of the learning activities in ECHOES are performed by Andy and the child in cooperation, with Andy assuming a more or less prominent role according to a particular activity's learning objective and the needs of the individual child. For example, if the goal is learning-by-imitation, Andy will adopt a leading role and will demonstrate different behaviours to the child. If the goal is engaging-in-reciprocal-interaction, Andy will give the child an opportunity to initiate a bid for interaction by waiting before initiating the interaction. There are the following two activities in ECHOES, which do not involve Andy: (i) bubble popping and (ii) free exploration of the magic garden. One or both of these activities are always used at the beginning of each session (see Figure 2 for a possible sequence of activities over the course of an ECHOES session). The child has full control over the interactions in these activities and our early pilot studies showed that children found these exploratory activities particularly rewarding (Alcorn et al. 2011).

As described in Section 2.1, a human partner is included in the interaction with the ECHOES environment. The child has opportunities to interact with both the AI agent and the human partner. It is important to note that the interaction with the agent was a pre-requisite for the child being able to complete the specific tasks. In contrast, interaction with the human was not required, and took the form of further encouragement and praise, demonstration of actions by the practitioners, and practitioners' readiness to respond to children's bids for interaction, e.g., when a child invited the practitioner to take a turn within an activity or pointed to something of interest on the screen. As the classroom is the intended environment for ECHOES, the human partner will be referred to as the practitioner, although in the study described in Section 4, this role was frequently adopted by a researcher.

\section{THE ECHOES AI AGENT AS A SOCIAL PARTNER}

Following the principles of autism and educational best practices, children need a responsive social partner. Such a partner needs to be able to model the behaviours targeted, to provide a socially

\footnotetext{
${ }^{4}$ Henceforth, we will refer to Andy, as Andy, the virtual character or the agent interchangeably.
} 
Table 1. Inventory of the ECHOES Activities

\begin{tabular}{|c|c|c|c|c|}
\hline & & & INTERACTION & INTERACTION \\
\hline ACTIVITY & TYPE & OBJECTS & WITH AGENT & WITH HUMAN \\
\hline $\begin{array}{l}\text { Bubble } \\
\text { popping }\end{array}$ & Exploratory & Bubbles & No & $\begin{array}{l}\text { Practitioner either } \\
\text { demonstrates that bubbles } \\
\text { can be popped or reacts to } \\
\text { the child's request to pop } \\
\text { bubbles }\end{array}$ \\
\hline Magic garden & Exploratory & $\begin{array}{l}\text { Magic cloud } \\
\text { can rains; } \\
\text { flowers; } \\
\text { flower basket; } \\
\text { pots; bouncy } \\
\text { balls }\end{array}$ & No & $\begin{array}{l}\text { Practitioner demonstrates } \\
\text { how objects can be } \\
\text { manipulated. Responds to } \\
\text { bids for interaction from the } \\
\text { child }\end{array}$ \\
\hline Ball sorting & $\begin{array}{l}\text { Closed-task } \\
\text { Reciprocal } \\
\text { interaction }\end{array}$ & $\begin{array}{l}\text { Balls and } \\
\text { coloured } \\
\text { boxes }\end{array}$ & $\begin{array}{l}\text { Andy: } \\
\text { - demonstrates how to sort balls; } \\
\text { - instructs the child; } \\
\text { - praises the child; } \\
\text { - signals end of the task }\end{array}$ & $\begin{array}{l}\text { Practitioner further } \\
\text { demonstrates the activity if } \\
\text { needed; responds to child's } \\
\text { requests to share the activity; } \\
\text { encourages the child to } \\
\text { engage in the activity } \\
\end{array}$ \\
\hline Tickling & Exploratory & None & $\begin{array}{l}\text { Andy responds to being tickled } \\
\text { by bending over and laughing }\end{array}$ & $\begin{array}{l}\text { Practitioner demonstrates } \\
\text { the activity if needed; } \\
\text { responds to child's requests } \\
\text { to share the activity; } \\
\text { encourages the child to } \\
\text { engage in the activity }\end{array}$ \\
\hline $\begin{array}{l}\text { Explore with } \\
\text { Andy }\end{array}$ & $\begin{array}{l}\text { Exploratory } \\
\text { Learning by } \\
\text { imitation }\end{array}$ & $\begin{array}{l}\text { Magic cloud } \\
\text { that can } \\
\text { produce rain; } \\
\text { flowers; } \\
\text { flower basket; } \\
\text { pots; bouncy } \\
\text { balls }\end{array}$ & $\begin{array}{l}\text { Andy: } \\
\text { - demonstrates the actions on } \\
\text { objects - takes turns with the } \\
\text { child to play with the objects } \\
\text { - praises the child }\end{array}$ & $\begin{array}{l}\text { Practitioner demonstrates } \\
\text { the activity if needed; } \\
\text { responds to child's requests } \\
\text { to share the activity; } \\
\text { encourages the child to } \\
\text { engage in the activity }\end{array}$ \\
\hline Rainy cloud & $\begin{array}{l}\text { Exploratory } \\
\text { Learning by } \\
\text { imitation }\end{array}$ & $\begin{array}{l}\text { Magic cloud; } \\
\text { flowers that } \\
\text { grow when } \\
\text { the cloud is } \\
\text { shaken }\end{array}$ & $\begin{array}{l}\text { Andy: } \\
\text { - demonstrates how shaking } \\
\text { cloud produces rain and this } \\
\text { causes the flowers to grow } \\
\text { - takes turns with the child to } \\
\text { shake the cloud } \\
\text { - praises the child }\end{array}$ & $\begin{array}{l}\text { Practitioner demonstrates } \\
\text { the activity if needed; } \\
\text { responds to child's requests } \\
\text { to share the activity; } \\
\text { encourages the child to } \\
\text { engage in the activity }\end{array}$ \\
\hline $\begin{array}{l}\text { Flower } \\
\text { growing }\end{array}$ & $\begin{array}{l}\text { Closed-Task } \\
\text { Reciprocal } \\
\text { interaction }\end{array}$ & $\begin{array}{l}\text { Magic cloud; } \\
\text { flowers that } \\
\text { grow when } \\
\text { the cloud is } \\
\text { shaken }\end{array}$ & $\begin{array}{l}\text { Andy: } \\
\text { - demonstrates the actions on } \\
\text { objects } \\
\text { - takes turns with the child } \\
\text { - praises the child } \\
\text { - Signals end of the task }\end{array}$ & $\begin{array}{l}\text { Practitioner demonstrates } \\
\text { the activity if needed; } \\
\text { responds to child's requests } \\
\text { to share the activity; } \\
\text { encourages the child to } \\
\text { engage in the activity }\end{array}$ \\
\hline Pick flowers & $\begin{array}{l}\text { Exploratory } \\
\text { Learning by } \\
\text { imitation }\end{array}$ & $\begin{array}{l}\text { Flowers, } \\
\text { basket }\end{array}$ & $\begin{array}{l}\text { Andy: } \\
\text { - demonstrates the action } \\
\text { - takes turns with the child to } \\
\text { fill basket with flowers } \\
\text { - asks for particular flowers to } \\
\text { be picked } \\
\text { - praises the child }\end{array}$ & $\begin{array}{l}\text { Practitioner demonstrates } \\
\text { the activity if needed; } \\
\text { responds to child's requests } \\
\text { to share the activity; } \\
\text { encourages the child to } \\
\text { engage in the activity }\end{array}$ \\
\hline
\end{tabular}


Table 1. Continued

\begin{tabular}{|c|c|c|c|c|}
\hline & & & INTERACTION & INTERACTION \\
\hline ACTIVITY & TYPE & OBJECTS & WITH AGENT & WITH HUMAN \\
\hline Stack pots & $\begin{array}{l}\text { Closed-task } \\
\text { Reciprocal } \\
\text { interaction }\end{array}$ & Pots & $\begin{array}{l}\text { Andy: } \\
\text { - demonstrates the action } \\
\text { - takes turns with the child } \\
\text { - asks for a particular pot to be } \\
\text { stacked } \\
\text { - praises the child } \\
\text { - Signals end of the task }\end{array}$ & $\begin{array}{l}\text { Practitioner demonstrates } \\
\text { the activity if needed; } \\
\text { responds to child's requests } \\
\text { to share the activity; } \\
\text { encourages the child to } \\
\text { engage in the activity }\end{array}$ \\
\hline $\begin{array}{l}\text { Fill basket } \\
\text { with flowers }\end{array}$ & $\begin{array}{l}\text { Closed-task } \\
\text { Reciprocal } \\
\text { interaction }\end{array}$ & $\begin{array}{l}\text { Flowers, } \\
\text { basket }\end{array}$ & $\begin{array}{l}\text { Andy: } \\
\text { - demonstrates the action } \\
\text { - takes turns with the child } \\
\text { - asks for a particular flower to } \\
\text { be put in the basket next } \\
\text { - praises the child for } \\
\text { completing action } \\
\text { - Signals end of the task }\end{array}$ & $\begin{array}{l}\text { Practitioner demonstrates } \\
\text { the activity if needed; } \\
\text { responds to child's requests } \\
\text { to share the activity; } \\
\text { encourages the child to } \\
\text { engage in the activity }\end{array}$ \\
\hline $\begin{array}{l}\text { Turn flower } \\
\text { into a ball }\end{array}$ & $\begin{array}{l}\text { Exploratory } \\
\text { Learning by } \\
\text { imitation }\end{array}$ & $\begin{array}{l}\text { Flowers; } \\
\text { bouncy balls } \\
\text { Flower centres } \\
\text { change into } \\
\text { bouncy balls } \\
\text { when flicked }\end{array}$ & $\begin{array}{l}\text { Andy: } \\
\text { - demonstrates the actions } \\
\text { - takes turns with the child to } \\
\text { turn flowers into bouncy balls } \\
\text { - praises the child }\end{array}$ & $\begin{array}{l}\text { Practitioner demonstrates } \\
\text { the activity if needed; } \\
\text { responds to child's requests } \\
\text { to share the activity; } \\
\text { encourages the child to } \\
\text { engage in the activity; helps } \\
\text { the child }\end{array}$ \\
\hline $\begin{array}{l}\text { Throw balls } \\
\text { through the } \\
\text { cloud }\end{array}$ & $\begin{array}{l}\text { Closed-task } \\
\text { Reciprocal } \\
\text { interaction }\end{array}$ & $\begin{array}{l}\text { Cloud, bouncy } \\
\text { balls; } \\
\text { Change colour } \\
\text { when they go } \\
\text { through the } \\
\text { cloud }\end{array}$ & $\begin{array}{l}\text { Andy: } \\
\text {-demonstrates the action } \\
\text {-takes turns with the child } \\
\text {-asks for a particular ball to be } \\
\text { thrown through the cloud } \\
\text { - praises the child } \\
\text {-Signals end of the task }\end{array}$ & $\begin{array}{l}\text { Practitioner demonstrates } \\
\text { the activity if needed; } \\
\text { responds to child's requests } \\
\text { to share the activity; } \\
\text { encourages the child to } \\
\text { engage in the activity }\end{array}$ \\
\hline
\end{tabular}

Bubble popping and magic garden free-play activities take place at the beginning of all sessions. Other activities are used based on each child's preferences (e.g., if a child likes a particular activity, it is likely that they will play with it more frequently) and whether or not the child has played with particular activities before, as the aim is for all children to play with all ECHOES activities.

credible real-time interaction, while also being able to engage children in structured learning. In other words, children need a social partner that is both (i) pro-active, i.e., has an ability to exhibit goal-directed behaviour by deliberating about, and actively trying to accomplish, its goals and by taking the initiative, and (ii) reactive, i.e., has the ability to perceive changes in the environment and react to them in a timely manner. Furthermore, such a partner needs to possess social ability to coordinate its actions with the actions of others - in our case, the child. Pro-activeness is important to maintaining the child's attentional focus and to fostering motivation. Reactivity is fundamental to adapting to children's changing needs and their cognitive and affective states. Social ability is crucial to maximising the child's sense of self-efficacy in communicating with the social partner. These requirements are fully in line with intelligent agent theory by Wooldridge and Jennings (1995). The theory, which continues to provide the basis for the design of intelligent agents, offers strong motivation for developing an autonomous planning-based agent within ECHOES that is able to act as a believable and educationally viable social partner to children. Such investment is further supported by existing evidence of the generalisable therapeutic and educational potential of virtual agents, e.g., (Bosseler and Massaro 2003; Grynszpan et al. 2008; Parsons and Cobb 2011; Strickland et al. 2007; Tartaro and Cassell 2008) and by ongoing successful research into applications of planning architectures as the basis for furnishing synthetic, socially enabled characters 
1

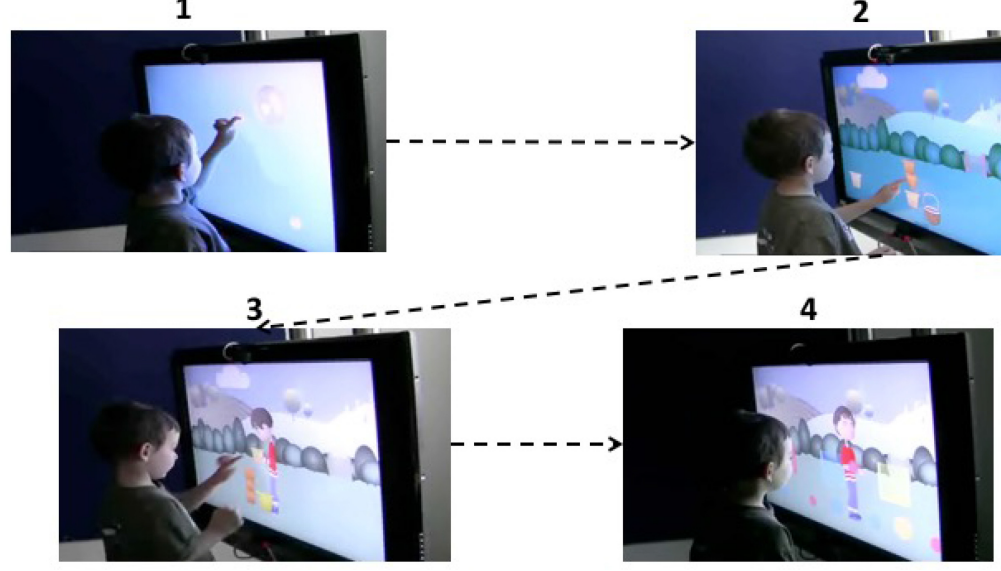

Fig. 2. A possible sequence of activities in one session. (1) Bubble popping; (2) magic garden free play, without Andy; (3) stacking pots with Andy; (4) ball sorting. The bubbles activity was always first, frequently followed by exploration without Andy. For children who are unable to concentrate over a long session, an activity with Andy directly followed bubbles.

with autonomous and believable behaviours (Anderson et al. 2013; Aylett et al. 2009; Cavazza et al. 2002; Kenny et al. 2007).

Therefore, the key component of the ECHOES environment is an autonomous planning-based agent that drives the decision making of the ECHOES AI agent. The agent utilises the FAtiMA planning architecture (Dias and Paiva 2005) that is based on the following: (i) AI planning techniques (Russell and Norvig 2003), (ii) an emotional model derived from the OCC cognitive theory of emotions (Ortony et al. 1988), and (iii) the appraisal theory of emotions (Smith and Lazarus 1990). It is a domain-independent agent architecture that provides the ECHOES agent with deliberative and reactive capabilities along with some basic socio-emotional competences. The two main mechanisms controlling a FAtiMA agent are appraisal and coping. Both mechanisms work at the reactive level, which affects the short-term horizon of the agent's behaviours, e.g., agent's timely reactions to a child's momentary actions, and at the deliberative level, which relates to the agent's long-term goal-oriented behaviours, e.g., scaffolding a child to complete a learning activity. Within each activity the agent's actions are controlled by the ECHOES intelligent engine and are based on the sequence of real-time updates produced by the Multimodal Fusion Engine. Further details of the rationale for the ECHOES software architecture and individual components are given in Foster et al. (2010) and Bernardini and Porayska-Pomsta (2013).

The agent's actions are either concrete demonstrations of social-communication skills targeted in ECHOES or actions performed to encourage the child to try and to practice them. Specifically, we define joint attention and symbolic use in terms of three component skills as follows: (i) responding to bids for interaction; (ii) initiating bids for interaction; (iii) engaging in turn taking. Andy, the agent, is able to demonstrate these skills in the following three different ways:

(1) Verbally - by using simple language or keywords (e.g., 'My/Your turn!' for turn-taking);

(2) Non-verbally - through gaze and gestures such as pointing at or touching an object, or using one of a small number of Makaton gestures ${ }^{5}$ (e.g., thumbs up for 'Well done');

(3) By combining verbal and non-verbal behaviours.

\footnotetext{
${ }^{5}$ Makaton is a language programme using signs and symbols to help people with language and learning difficulties to communicate. https://www.makaton.org/
} 
Andy is able to make requests, greet the child by name, comment on events happening in the magic garden and apply exploratory actions to the interactive objects. This variety of behaviours is intended to make the interaction dynamic enough to keep the child engaged and to foster generalisation of skills practiced, while retaining a degree of predictability that is essential to supporting the child's attentional focus and sense of safety. Andy always provides the child with positive feedback, especially if the child responds to his bids for interaction correctly. If the child does not perform the expected action, Andy first waits for the child to do things at their own pace and then intervenes by demonstrating the action. To support the child's interaction within specific activities, Andy always explains a new activity to the child using simple language and precise instructions (e.g., 'Let's pick ten flowers'). The importance of providing the children with positive feedback was emphasised by teachers who contributed to the design of Andy's behaviours as key to reducing children's anxiety in social interactions and helping them experience a sense of self-efficacy.

ECHOES also incorporates a practitioner graphical user interface (henceforth referred to as the GUI) through which the practitioner can control the choice and duration of the learning activities. The GUI aims to cater for the substantial diversity in individual children's needs and preferences. As well as enhancing the ECHOES' real-time interpretation of the child's needs, for example the need to repeat an activity that a child might have found particularly enjoyable or to make Andy repeat a specific action if the practitioner deemed it beneficial for a particular child, the GUI also provides a tool for creating an environment in which no opportunity is lost to engage children in social interaction and communication. The GUI is accessed through a separate screen, not visible to the child, so as not to interfere with the flow of the interaction.

\section{STUDY DESIGN}

We conducted a multi-site intervention study in real school contexts to examine the potential impact of the ECHOES environment use on social communication skills in children with ASC. Specifically, we focused on children's ability to initiate or respond to bids for interaction by others (APA 2013). In doing so, we examined the efficacy of the ECHOES environment, i.e., its potential to have a desired effect, as opposed to its effectiveness, i.e., definitive proof that it led to the desired outcome, in this case to the acquisition of social interaction skills (see, e.g., (Rao et al. 2008) for an elaboration of the definitions of efficacy vs. effectiveness). This distinction means that we have not been able to control for all factors that may potentially have confounded our findings. However, we believe that the methods we employed to create, deploy, and evaluate the ECHOES approach are in line with observations and postulates for autism intervention and education in-the-wild (Parsons et al. 2013).

The study used a within-subjects design, looking at changes in initiations/responses across condition (ECHOES vs. non-ECHOES) and over time (the beginning, middle and end phases of interaction with ECHOES). As we were particularly interested in how initiation/response patterns changed over time for children with ASC, a matched control group was neither appropriate, nor feasible, given the profiles of our participants. Many of the children with ASC who participated in the ECHOES studies were characterised as having learning difficulties, confirmed by pre-test assessment (see Section 4.1), and most had been assessed as developmentally delayed. In terms of their language ability, many were at the social $(\mathrm{SP})^{6}$ or language partner $(\mathrm{LP})^{7}$ stage, and the others were at the conversational partner $(\mathrm{CP})^{8}$ stage, as defined within SCERTS. Owing to their profiles,

\footnotetext{
${ }^{6}$ Child uses fewer than three words/phrases referentially, regularly, with communicative intent.

${ }^{7}$ Child uses more than three words/phrases referentially, regularly, with communicative intent.

${ }^{8}$ Child uses at least 100 words/phrases referentially, regularly, with communicative intent and can use at least 20 different word combinations that are creative.
} 
there can be no functionally appropriate comparison group for these children and hence, the traditional 'group-matching' method is not appropriate for direct comparison, particularly when it is based on IQ (see Dennis et al. (2009) and Rao et al. (2015) for further discussions of why this is problematic).

Nevertheless, the so-called 'lower-functioning end of the spectrum' is often under-researched, overlooked and perhaps even under-estimated (Mottron 2004). It is therefore important to ensure that individuals considered to be 'low functioning' are represented in research, to avoid bias in the literature. Furthermore, it may be that this group has the greatest potential to benefit from environments such as ECHOES.

Similar to Whalen and Schreibman (2003), who included a group of TD children in their study in order to 'identify "normal" levels of social behaviours', we also included a group of TD children in the study. They were not considered as a control group, but allowed us to obtain a broad measure of 'typical' social interactions (i.e., initiations/responses) across the various study conditions, in effect providing a non-clinical point of reference.

Our specific research questions for the study are as follows:

(1) Do ASC children show an increased response to bids for social interaction while using the ECHOES environment?

(a) Does this pattern differ between the virtual agent and human practitioner?

(2) Do ASC children show an increase in the number of initiations for social interaction made whilst using the ECHOES environment?

(a) Does this pattern differ between the virtual agent and human practitioner?

(3) Do any increases in response/initiations transfer to other contexts?

\subsection{Participants}

Five schools and specialist units for children with ASC were identified and invited to participate in the study. The study design was pilot tested in a further school over 2-3 sessions with four children with ASC. Following revisions to the study design and to the system based on the pilot, ECHOES was deployed at four sites (five schools) across the UK: three special schools ${ }^{9}$ and two mainstream schools. One of the mainstream schools had a unit ${ }^{10}$ dedicated to working with children with ASC and other learning difficulties. The second shared a site with a school for children with severe, complex, and enduring additional support needs, including autism. A group of TD children was recruited from each of the two mainstream schools. Figure 3 provides an overview of initial and final numbers of child participants, including information on the tests administered.

Twenty-nine children with a previous ASC diagnosis were exposed to ECHOES across the four sites, and their interactions were video-recorded. These children had previously received a diagnosis of autism via qualified authorities and professionals. Children recruited from the three special schools had also been assessed as having learning difficulties. Although it would not have been either appropriate or ethical to re-diagnose the children solely for the purpose of this project, we used the Social Communication Questionnaire (SCQ) and British Picture Vocabulary Scales (BPVS) to gather further evidence about the children's specific difficulties.

Children who had less than 45 minutes of interaction with ECHOES, or who did not take part in a minimum of three ECHOES sessions, were excluded from the analysis, reducing the ASC participant numbers from 29 to 19 . The main reason for attrition was illness and other absence. Additionally, a small number of children chose not to continue the use of ECHOES at different points;

\footnotetext{
${ }^{9}$ For children with complex, long-term additional support needs, primarily severe learning disabilities, severe social communication difficulties and/or autism.

${ }^{10}$ Note that some schools refer to such units as 'resource bases'.
} 


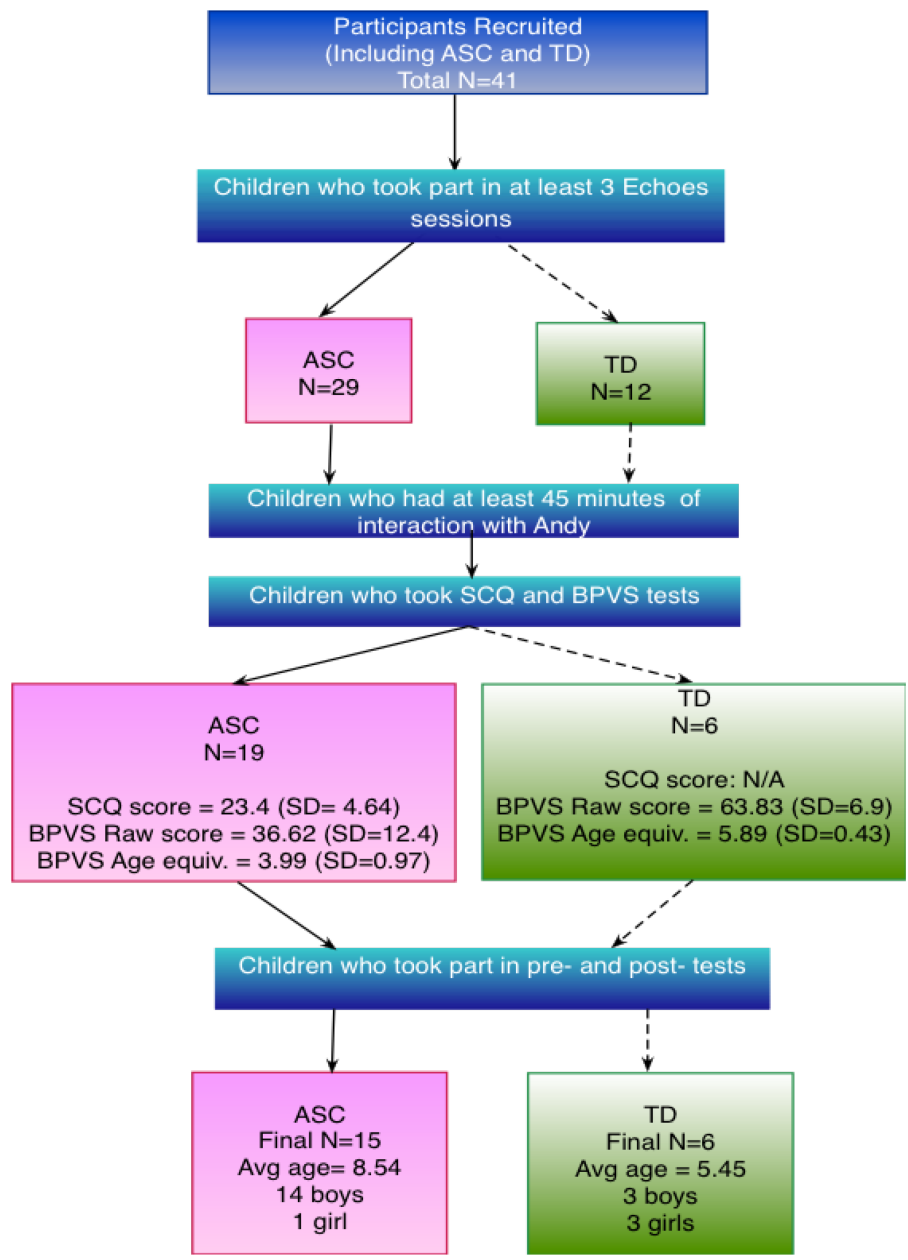

Fig. 3. A summary of participants' selection, numbers, and the corresponding tests administered.

therefore, their data was too incomplete to provide a meaningful basis for analysis. The children who did not want to play with ECHOES were not distinguished from the remaining children by any diagnostic traits except for potential over-sensitivity to the sensory features of ECHOES, such as garden sounds. Other factors may have played a role, for example, children being away from their typical classroom environment, lighting in the room and time of day and week - afternoons and end of the week tended to be the most difficult owing to children's tiredness.

Also excluded were children who did not participate in both pre- and post- 'table-top' assessments, further reducing this to 15 children with ASC (see Figure 3). In addition, the TD children in one of the two mainstream schools worked in pairs (at the school's request) so their data was not comparable with individual use; thus, they were also excluded from the analysis. As a result, a subset of 15 ASC children was included in the analysis presented here.

The ASC group $(N=15)$ had an average age of 8.54 years (range $4-14$ years) and included one girl. Confirmation of the ASC diagnosis was provided by the SCQ, which was completed by a caregiver. The average SCQ score was $23.4(S D=4.64)$, i.e., higher than the cut-off score of 15 (see Barnard-Brak et al. (2016) for a discussion about cut-off scores for the SCQ regarding sensitivity 
Table 2. Participant Data was Anonymised; School Type is Learning Difficulties (LD) or Mainstream (MS); for Language Level See Above

\begin{tabular}{|c|c|c|c|c|c|c|}
\hline PCode & School type & $\begin{array}{c}\text { SCERTS level } \\
\text { (SP, LP, CP) }\end{array}$ & $\begin{array}{c}\text { Age: } \\
\text { years, months }\end{array}$ & Gender & SCQ score & $\begin{array}{c}\text { BPVS } \\
\text { age equiv. }\end{array}$ \\
\hline RD11 & LD/ASC & LP-CP & 7.6 & $\mathrm{M}$ & 23 & 3.3 \\
\hline AM12 & $\mathrm{LD} / \mathrm{ASC}$ & $\mathrm{CP}$ & 8.2 & $M$ & 23 & 5.0 \\
\hline OM16 & LD/ASC & $\mathrm{LP}$ & 7.8 & $\mathrm{M}$ & 25 & 3.2 \\
\hline GJ26 & LD/ASC & $\overline{\mathrm{LP}}$ & 13.7 & $M$ & 18 & $\mathrm{NC}$ \\
\hline SD27 & LD/ASC & LP & 13.1 & $\mathrm{M}$ & 17 & 4.2 \\
\hline CM29 & $\mathrm{LD} / \mathrm{ASC}$ & SP-LP & 13.8 & $M$ & 32 & 3.2 \\
\hline RD30 & $\mathrm{LD} / \mathrm{ASC}$ & $\mathrm{CP}$ & 13.8 & $M$ & 28 & $\mathrm{NC}$ \\
\hline ALH31 & LD/ASC & $\mathrm{CP}$ & 12.8 & $\mathrm{~F}$ & 26 & 5.11 \\
\hline HB51 & MS/ASC & SP & 4.10 & $M$ & 27 & $<3$ \\
\hline HK53 & MS/ASC & LP & 5 & $\mathrm{M}$ & 23 & 3.2 \\
\hline KL54 & $\mathrm{MS} / \mathrm{ASC}$ & $\mathrm{CP}$ & 5.11 & $M$ & 14 & 5.10 \\
\hline$\overline{\text { DSS55 }}$ & MS/ASC & $\mathrm{CP}$ & 5.9 & M & 20 & 4.3 \\
\hline EW56 & MS/ASC & $\mathrm{CP}$ & 5.5 & $\mathrm{M}$ & 23 & 4.3 \\
\hline MG78 & LD/ASC & $\mathrm{LP}$ & 6.8 & $\mathrm{M}$ & $>15$ & $<3$ \\
\hline MD80 & $\mathrm{LD} / \mathrm{ASC}$ & $\overline{\mathrm{LP}}$ & 7.4 & $M$ & $>15$ & $<3$ \\
\hline SM57 & MS/TD & - & 5.5 & $\mathrm{~F}$ & - & 6.0 \\
\hline GW58 & MS/TD & - & 5.2 & $\mathrm{~F}$ & - & 6.6 \\
\hline MD59 & $\mathrm{MS} / \mathrm{TD}$ & - & 5.6 & $\mathrm{~F}$ & - & 5.0 \\
\hline NO60 & $\mathrm{MS} / \mathrm{TD}$ & - & 5.6 & $M$ & - & 6.7 \\
\hline TW61 & $\mathrm{MS} / \mathrm{TD}$ & - & 5.4 & $\mathrm{M}$ & - & 6.9 \\
\hline HD62 & $\mathrm{MS} / \mathrm{TD}$ & - & 5.4 & $\mathrm{M}$ & - & 6.9 \\
\hline
\end{tabular}

BPVS: 2 were not completed due to behavioural difficulties (NC); 3 were assessed as below the 3-year age cut-off for this version. SCQ: for 2 children data was provided by the school as $>15$ cut-off.

and specificity). Verbal language ability was assessed using the 2nd edition of the BPVS. The mean raw BPVS score was 36.62, giving a mean age equivalent of 3.99 years $(S D=0.97)$, significantly lower than the group's chronological age. It should also be noted that seven children had BPVS scores that were too low to provide age equivalence. The group of 15 children with ASC included 5 younger children (aged 7-8 years) and 5 older children (aged 13-14 years) with learning difficulties in addition to the diagnosis of autism. Three further children were assessed, using BPVS, as having a raw age equivalent more than 1 year below their chronological age. Participant information is provided in Table 2.

Twelve TD children were recruited to provide the reference group. As noted above, six were then excluded from the analysis because they had been working in pairs. The average age of the TD group $(N=6)$ was 5.45 years and included three girls. The TD children did not complete the SCQ. Average BPVS raw score was 63.83 and age equivalence was 5.89 years. Both the age and BPVS scores differed significantly between TD and ASC groups $(p<.001)$.

The study design was approved by the ethics board of the site managing the evaluation, and the approval was further reviewed and accepted by all of the participating sites. Ethics approval covered all participatory design, formative evaluation, and other studies, in addition to the multiple site study presented in this article. In all cases, information sheets and consent forms were provided to potential participants, parents/guardians, practitioners and teachers. Language appropriate consent forms and information sheets were provided for all children, and read aloud to them if necessary. 

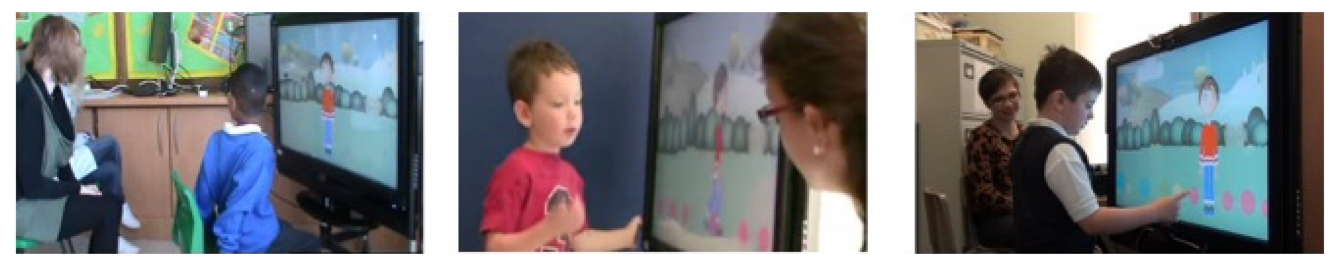

Fig. 4. Children using ECHOES with the researcher at three different evaluation sites.

\subsection{Materials and Procedure}

Given that the study was to be conducted concurrently on multiple sites, researchers were trained in the application of the study procedure through workshops and reference to the ECHOES 'Manual for Researchers', which was specially developed by the evaluation team to ensure consistency across all sites. The training workshops and manual covered all aspects of the study procedures, including training in using the BPVS, checklists for preparation for working in schools and control of the ECHOES environment. The manual also contained detailed plans for the study, including guidance on the placement of cameras, selection, and order of activities, and interacting with and supporting the participants. In addition, a detailed specification was developed in relation to data collection and storage.

Prior to the children's interaction with ECHOES, the researchers assigned to each school spent several sessions observing the children with whom they would be working in the classroom settings. The researchers participated in classroom activities, allowing the children to become familiar with them. ECHOES was installed in quiet, dedicated spaces in each school. Individual children interacted with the environment whilst their interaction was monitored and structured by the human partner/practitioner (Figure 4). Depending on their preferences, children sat on a chair or stood in front of the screen while the practitioner (and classroom assistant when necessary and available) sat to the side of the screen out of the child's immediate line of sight. Practitioners were able to control the various aspects of the ECHOES environment if needed through the GUI designed for this purpose (see also Section 3). At three of the five sites, the researchers acted as practitioners. At the other two sites, teachers and teaching assistants were trained to take on this role, and worked in conjunction with the researchers.

To assess each child's initial social communication skills, their behaviour was video-taped during (i) free-play at school (e.g., in the playground), (ii) usual classroom activities, (iii) a structured group turn-taking exercise in the classroom, and (iv) a structured one-on-one table-top turn-taking activity. These also served as familiarisation activities, allowing the children to get to know the researchers for the purpose of reducing children's anxiety in preparation for the sessions with ECHOES. Behaviours observed in these videos were coded and quantified using the SCERTS-based ECHOES annotation scheme described in Section 5.

The structured table-top turn-taking activity involved the child playing with two toys (a bubble gun and a remote-controlled robot) on a table-top, and a human practitioner (Figure 5). The design of these activities was informed by the behavioural assessments used in diagnostic tools, such as ADOS (Lord et al. 2012). The practitioner was instructed to take turns with the child in controlling the toy, using joint attention and pointing, in order to direct the child's attention to objects on the table-top and to respond to any bids for interaction made by the child. They were also instructed to provide opportunities for the child to initiate, e.g., by remaining quiet for short periods.

After the initial table-top pre-test, each child was given the opportunity to play with the ECHOES environment for periods of 10-20 minutes, several times a week over a six-week period. The structure of each session was decided collaboratively by the child and the practitioner, 

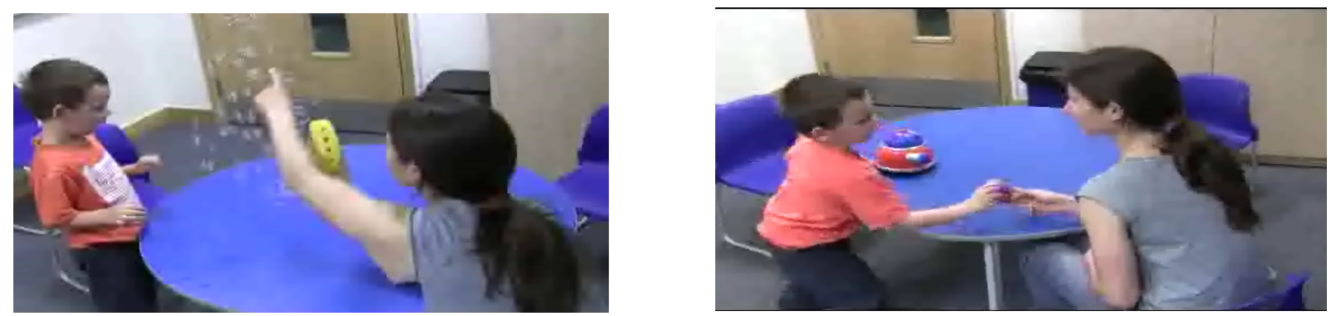

Fig. 5. The table-top activity used to assess social communication skill before (pre) and after (post) ECHOES use. Left $=$ bubbles activity. Right $=$ robot activity.

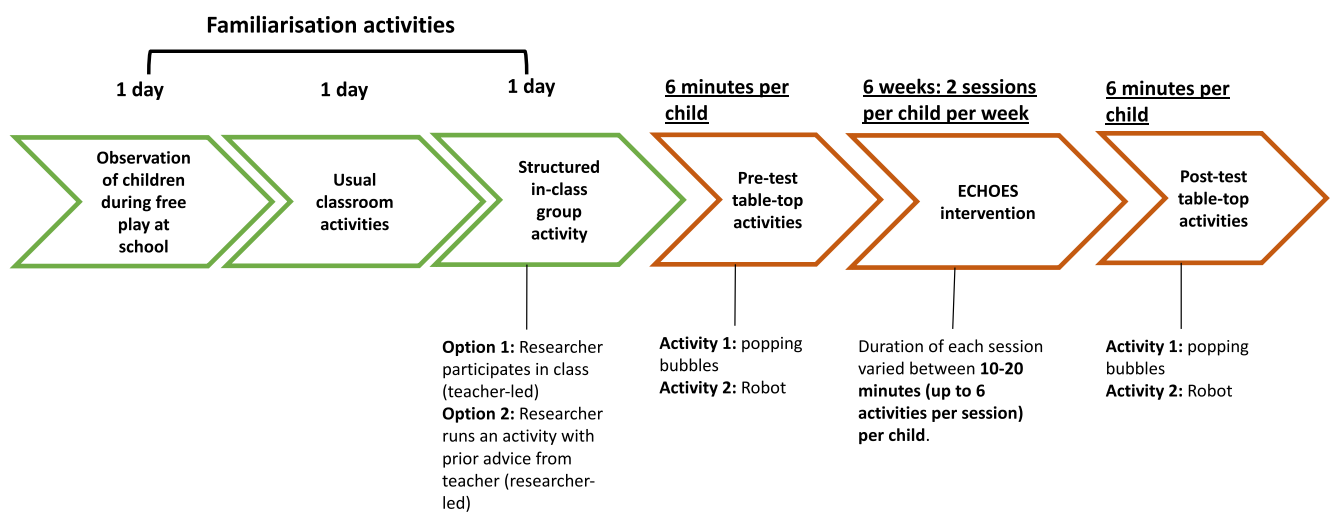

Fig. 6. ECHOES study procedure, detailing the pre-/post-testing and main intervention along with specific timings for each.

with the practitioner suggesting that learning activities to engage with and when to move between them. All sessions began with the bubbles activity and progressed to the magic garden free-play. However, the time spent on each activity was decided by the practitioner or upon child's request, depending on how engaged the child appeared to be. As the number of activities increased in each subsequent session, less time was spent on these two initial activities. The overview of the entire procedure employed in ECHOES is shown in Figure 6.

The complexity of the activities increased with each new session, and the ECHOES agent was gradually introduced to act as a social partner to the child. The practitioners were instructed to progress to new activities when they judged the child had grasped the current activity, had become bored or upon child's request. Learning activities included in the evaluation are as follows: Bubble popping, magic garden free-play, ball sorting, tickling Andy, Explore with Andy, rainy cloud, flower growing, pick flowers, stack pots, turn flower into a ball, turn flowers into bubbles, and throw balls through the magic cloud. The AI agent was used in most of the learning activities, but the extent to which he was critical to the goal of an activity varied. For instance, during the early exploratory activity Andy would be present and children could tickle him or hand him objects but he would not initiate interaction. Later activities, such as sorting coloured balls into boxes, required turn-taking: Andy would point to request specific balls that the child could hand to him.

If the child became distressed, distracted or disengaged from ECHOES during a session, the session would be terminated and the child would return to their class. In the small number of cases where this happened, and impeded the child's use of ECHOES, the child's data was removed from the final analysis sample, as already reported in Section 4.1. 
All ECHOES sessions were video-taped. At the end of the six weeks of children using ECHOES, the pre-test activities were repeated. For conciseness, we report only the results of the table-top activities.

\section{DATA CODING SCHEME: ADAPTED SCERTS ASSESSMENT PROTOCOL (SAP)}

The coding system used to assess the video data collected during the summative evaluation is an adapted version of the SCERTS Assessment Process (SAP) (Prizant et al. 2006). The original SAP is a curriculum-based assessment tool for gauging individual children's capacity to use certain skills and to engage in tasks across meaningful, everyday contexts. The emphasis is on understanding the functional role of an individual child's behaviours and communicative acts, rather than solely identifying the deficits. Assessment of a child's level of social and communicative competence is based on detailed behavioural criteria derived from the developmental and autism literature, rather than by reference to group norms (see overview in Prizant et al. (2006): Volume 1, Chapter 7).

Despite its orientation toward rapid, on-going assessment in practice, the SAP provided an invaluable starting point for the data coding in ECHOES, owing to (i) the wide range of sociocommunicative behavioural criteria included in the SAP, and (ii) the fact that many high-level behaviours (e.g., requesting) have already been decomposed into smaller, individual criteria (e.g., request food, request help, request comfort). Moreover, these criteria are context-independent, and are therefore relevant to a wide range of interactions in which there may be no prior list of 'relevant' or 'possible' child behaviours. This is very different from the narrower, context-dependent data coding schemes for assessments such as ADOS (Lord et al. 2012), or the Early Social Communication Scales (ESCS) (Mundy et al. 2003), which dictate the application of pre-specified, standardised materials to very structured one-on-one interactions between the child and an adult 'tester', whose task is to elicit specific behaviours from the child. The SAP's range and flexibility is appropriate as a starting point for the varied ECHOES evaluation contexts (classroom data, structured table-top activities, and interaction with the virtual environment) because it allows us to account for both the use of technology-enhanced learning and the real-world school context of the study. Whilst other coding schemes, such as Bauminger (2002) and Hauck et al. (1995), are designed to be used in natural environments, their coding schemes do not provide the hierarchical levels of categories, or the operationalisation of the lower levels of detail, that SAP does.

In the modified SAP for ECHOES coding scheme (SAP-E), we have largely kept the spirit and the behavioural criteria of the original SAP, while making some changes in order to render it more useful as a research tool in the context of ECHOES. In particular, the SAP-E uses a modified subset of the behavioural codes of the original SCERTS framework, and adds several new codes that capture additional information specific to ECHOES. The behavioural codes are applied incrementally to allow us to capture information about a child's behaviours at multiple levels of detail. For example, at a high level, a given behaviour may be coded as a verbal response to the virtual character, but can also be coded as constituting a greeting, and as being an instance of exact echolalia (i.e., imitation of another person's speech). The current article reports the results related to the higher level codes, rather than the specific results for these more detailed codes.

The main changes between SAP and SAP-E can be summarised as follows:

(1) Shift to counting instances of behaviours instead of estimating frequency of use;

(2) Limit coding to ECHOES-relevant socio-communicative behaviours;

(3) Provide more detailed, stringent definitions of child initiation;

(4) Add codes that define social partners' initiations and responses to the child;

(5) Add codes that define 'missed opportunities' for the child to respond to social partners. 
While these changes may seem substantial, we still consider the SAP-E to be an adapted and extended version of the SAP, rather than a completely new coding scheme. This is because the SAPE's focus remains on investigating communicative competence in a flexible, unscripted interaction that, in addition to the child, may involve multiple social partners and objects at various points. Furthermore, most of SAP-E's behavioural codes follow the SAP verbatim, or have very minor alterations (i.e., to specify that they apply to the virtual character, or to remove parts of the code clearly irrelevant to ECHOES). The main changes introduced through SAP-E relate to bridging the gap between the formative, practice-focused uses of the SAP, and the definitional precision, and contextual information required to turn it into a tool able to produce research-quality data about child communication in a technology-enhanced environment.

\subsection{Applying the Coding Scheme to ECHOES Data}

Video from each participant included in the analysis was sampled at the beginning, middle, and end of the ECHOES intervention period, excluding child rest breaks, technical malfunctions, and footage of other activities not specifically related to ECHOES. Each sample analysed comprised 15 minutes of child-ECHOES interaction using activities in which the agent was present, as well as the transitions between such activities. Samples were selected as follows: beginning (beg) samples started in the session where the virtual agent was first introduced, ending (end) samples started with the virtual agent's exit from the final session with ECHOES (with the 15 minutes of qualifying footage counted back from that point), while the middle (mid) sample was drawn from the child's middle session with the virtual agent.

Each video was first coded by a researcher trained in the SAP-E. Training included extensive practice on ECHOES pilot data, iteratively discussing and amending the coding until it was close to the previously coded and agreed 'master' version for one training video. Ten first-coders (selected from the authors and associated students) were used in total, all trained to be able to accurately reproduce the SAP-E coding of the training video before progressing. In coding the final evaluation data, coders were blind to the child's diagnostic category (ASC or TD) and the video's phase (e.g., pre-test or post-test table-top; beg, mid, or end of the ECHOES intervention), though differences in context such as table-top vs. ECHOES were self-evident. Codes were applied using the ELAN Linguistic Annotator. ${ }^{11}$ ELAN allows multiple, overlapping codes to be attached to sections of video through a mixture of free-text entry and menus of pre-defined labels, facilitating a high degree of flexibility in identifying and labelling child-partner interactions. After first coding was completed for all videos, all annotations were fully moderated by one of two second coders in order to improve confidence in the final analysis. Whenever moderators disagreed with first codes and could not resolve the conflict easily, the two moderators conferred and reached agreement. Full moderation was used instead of partial second-coding for various reasons as follows: (1) with ten independent coders, any calculation of inter-rater reliability (IRR) would be difficult to derive meaningfully; (2) by having two moderators view all annotations and reach agreement we were aiming for a high level of consistency in the application of the coding scheme across all videos rather than simply confidence in the amount of variation in the codes; (3) the substantial variation in ability of the children documented in the videos combined with the number of coders, meant that after experiments with IRR during piloting of the annotation scheme it became clear that a highlevel overview of all children was required when applying the coding scheme. Final annotations were exported as tab-delimited text for further analysis.

\footnotetext{
${ }^{11}$ ELAN annotation tool for complex data annotations on video and audio resources: ELAN: Max Planck Institute for Psycholinguistics. The Language Archive: Elan 4.1.2. URL http://tla.mpi.nl/tools/tla-tools/elan/
} 

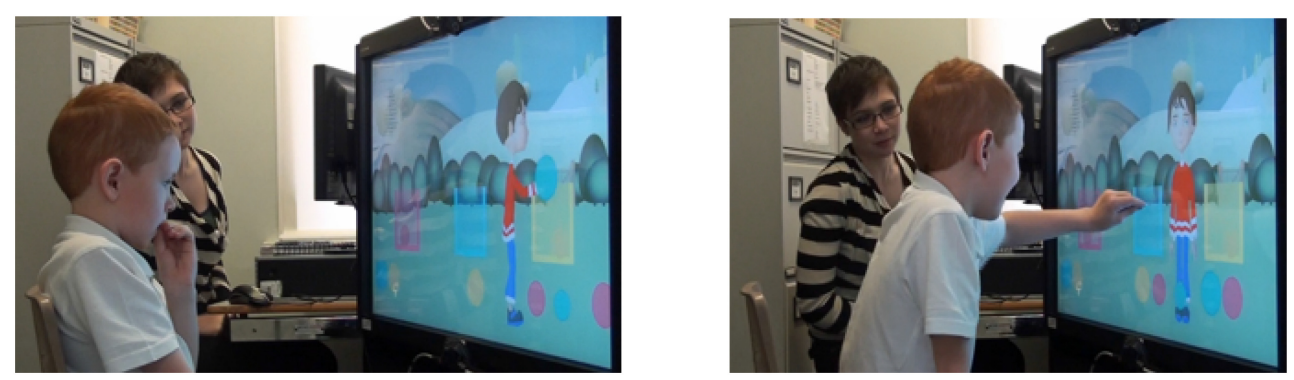

Fig. 7. Left: A child watches Andy make a sorting mistake. Right: The child contact points to the blue box and tells Andy 'Right here!'.

\subsection{Behavioural Codes Discussed in This Article}

For the purpose of the analysis presented in this article, and in line with our hypotheses, we focus on the following three high-level categories of socio-communicative behaviours that are less frequently used by children with ASC:

(1) Child's response to bids for interaction from a social partner, including

(a) Verbal and non-verbal responses to partner's verbal and non-verbal initiations;

(b) Following the reference of a partner's pointing.

(2) Child's initiation of bids for interaction to a social partner, including

(a) Use of pointing to direct a partner's attention;

(b) Requesting (objects, help/actions, activities);

(c) Protesting undesired actions,

(d) Other verbal and non-verbal bids not otherwise specified, including commenting on objects or events.

(3) Child's social behaviour towards partners, in particular

(a) Using gaze for social referencing (i.e., looking towards a partner for information) and social sharing (i.e., initiating joint attention through a combination of gaze and gesture to convey enjoyment and interest);

(b) Monitoring the attentional focus of the partner in an on-going activity;

(c) Securing the attention of the partner;

(d) Greeting the partner;

(e) Facilitating continuation of turn taking.

In SAP-E, each behaviour is listed as a high-level category description that encompasses multiple specific codes, and is supported by specific examples of child behaviours. In many cases, a behaviour could feasibly be classified as fulfilling more than one behavioural objective, and hence be coded under all categories that capture the relevant information about that behaviour. The current analysis also incorporates information on social partners' initiations and responses to the child, as well as missed opportunities for children to respond to social partners' bids for interaction (discussed in Section 5). Finally, as an additional and more qualitative source of information, the analysis draws on concrete, i.e., verbatim examples of children's speech directed to the virtual agent throughout their ECHOES sessions. For example, in Figure 7, the child observes Andy trying to put a blue ball in the yellow box. He leans forward and touches the blue box and tells Andy 'Right here!' then, with his other hand, touches the blue box twice and shouts: 'That one!'. In this example, we see the child initiating a bid for interaction to the AI social partner, and using pointing to direct a partner's attention. 


\section{RESULTS}

The analysis presented is based on the pre-ECHOES table-top videos, three 15-minute ECHOES sessions involving the AI agent (beginning, middle, and end of the intervention period), and the post-ECHOES table-top sessions. Our analysis focuses on children's initiations of and responses to bids for interaction to social partners, including (i) the AI agent and (ii) the human practitioner. In order to be coded, behaviours must be relevant to the ECHOES system in some way (e.g., the child initiating to tell the researcher about a field trip, say, would not be coded under the SAP-E).

\subsection{Frequency of Children's Responses to a Social Partner}

Given that the number of initiations made by the partner (both the HUMAN practitioner and the AGENT) may vary substantially across sessions and across children, the successful responses made by the child will be expressed as a proportion: ranging from 1 (all initiations responded to) to 0 (no initiations responded to). Given that lesser responsiveness to initiations by a social partner is a diagnostic trait of ASC (e.g., as measured by ADOS), it was predicted that our ASC children would exhibit lower proportions of responses both during the pre-ECHOES table-top session and throughout ECHOES, as compared to their TD peers. Of interest here is whether these proportions change, and how they vary across the HUMAN practitioner - a socially complex, but more reactive and reliable social partner, and the AGENT - a simpler, more predictable partner, but with limited interactivity compared to the human.

The mean proportion of ASC children's responses to the practitioner's bids for interaction during the table-top pre-test was $0.66(S D=0.17)$, i.e., significantly less than the reference proportion for TD children (overall mean $=0.87, S D=0.17, t(21)=-3.412, p<0.01$ ). ${ }^{12}$ This confirms that our ASC sample began the study with significant impairment in social responsiveness compared to an unmatched TD sample.

What is clear from the mean proportion of responses displayed in Figure 8 is the increase in responses during the use of ECHOES. A repeated-measures ANOVA performed on the proportion of responses to HUMAN initiations across the five phases (pre- and post-table-top, and beginning, middle, end of ECHOES sessions) showed a significant main effect of phase $(F(4,56)=$ $4.167, p<0.01)$, which can be attributed to the end time point showing a greater proportion of response $($ mean $=0.813, S D=0.214)$ compared to the pre-test $($ mean $=0.656, S D=0.171 ; t(14)=$ $-3.72, p<0.01$ ). This increase also brings the ASC responsiveness to a level comparable to that of the TD group. However, this increase in responsiveness does not transfer outside of ECHOES to the table-top activity, as shown by the post-test (mean $=0.711, S D=0.142$ ), the results of which are not significantly different to the pre-test, $t(14)=-1.637, p=0.124, n . s$.$) .$

The key difference seen in Figure 8 is the low proportion of child responses to AGENT initiations (Figure 8, right panel; mean $=0.59, S D=0.22$ ) compared to the responses to the HUMAN practitioner (Figure 8, left panel; 0.8). This difference is significant within the ECHOES sessions $(F(1,25)=9,588, p<0.01)$ and may be due to issues with Andy's temporal contingency on the child's interactions. Specifically, while the planning architecture used to underpin the agent's behaviours gave the agent decision-making capabilities, and enabled greater responsiveness to the child, the agent's reactions were at times slightly delayed owing to a current plan needing to complete execution before it could react to the child's next action. This was particularly an issue with children who did not observe turn-taking and did not wait for Andy to finish what he was doing.

\footnotetext{
${ }^{12}$ Note that as there was no significant difference for the TD group across the various phases, and that the group was acting as a non-clinical point of reference rather than as a control, the mean of the TD group across all phases has been represented as a red dashed line for both HUMAN and AGENT responses in Figures 8 and 9 (95\% confidence intervals for the TD distribution are denoted as red dotted lines).
} 


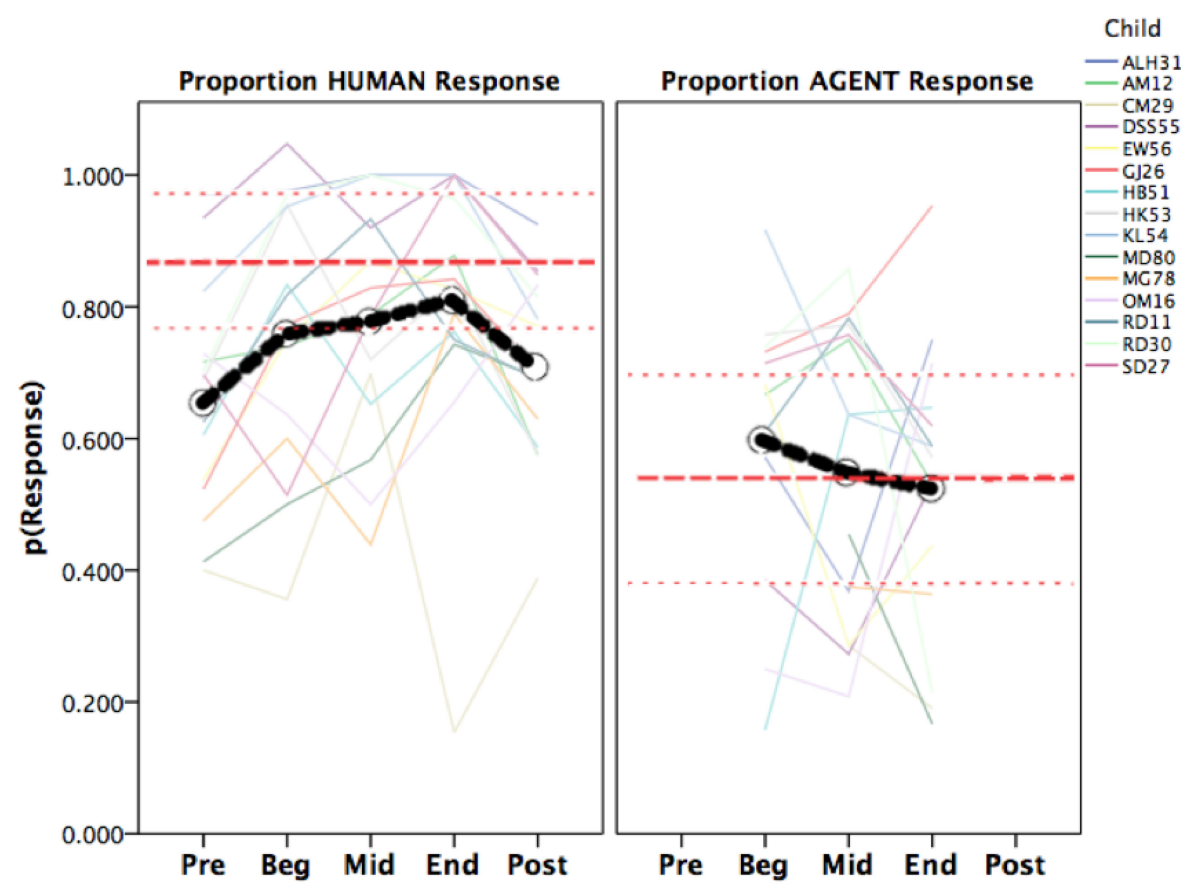

Fig. 8. Mean proportion of child responses to partner initiations (black dashed line), split by the HUMAN practitioner (left panel) or Andy the AGENT (right panel) across the pre-table-top, beginning, middle, and end ECHOES sessions and the post-table-top session. Reference mean proportion of TD children's responsiveness to initiations is represented as the red dashed line (the average proportion of responses over all five time periods) with $95 \%$ confidence intervals for the TD group represented as red dotted lines. Background coloured lines represent individual participant values at each session (anonymised IDs tally with Table 2).

The slight decrease in response proportion over time does not reach significance $(F<1)$. Note that the TD reference responsiveness to Andy (Figure 8, right panel, red dashed line) was similarly low, suggesting that the ASC children did not find Andy any more difficult as a social partner than the TD children.

\subsection{Frequency of Children's Initiations to a Social Partner}

Initiating can be considered more difficult than responding to a partner, because it relies crucially on the initiator's motivation to communicate with another person as well as their ability to communicate without prompting. In contrast, the form and the function of the expected type of response will be directly or indirectly prompted by the partner's initiation, giving the child clues not only that a response is expected, but also often what form of response is required.

The videos were coded for initiation behaviours directed to both the HUMAN practitioner and the AGENT, and considered across verbal, non-verbal, and combined initiations. Initiation behaviour is more difficult to standardise as (i) we do not know how many initiations should be expected per child and per session, and (ii) the different learning activities and level of ability of each child may substantially impact the frequency of their initiations.

The results of the analysis focusing on the frequency of initiations to HUMAN, illustrated in Figure 9 (left panel) by a black dashed dotted line, reveal that the ASC children make more initiations before and during ECHOES use than would normally be expected given the profile of this 


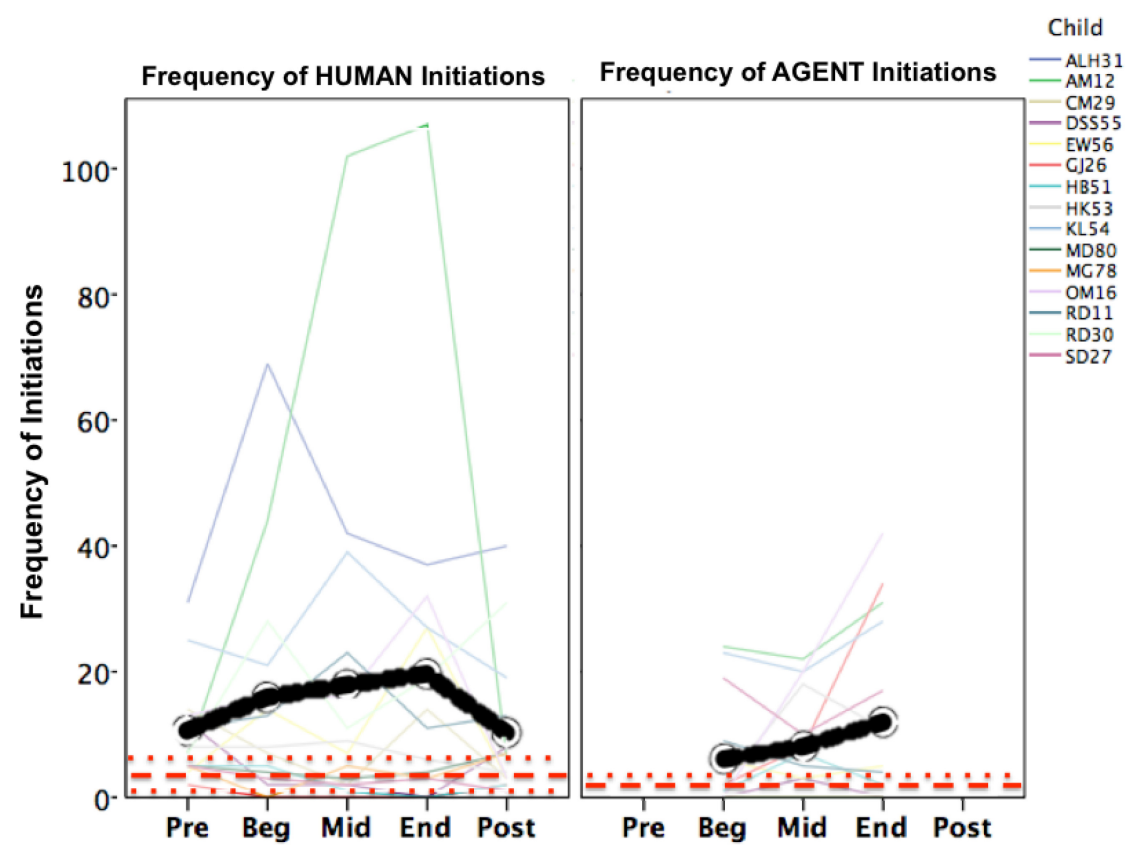

Fig. 9. Mean frequency of initiations made by child (black dashed line) to the HUMAN practitioner (left panel) or to Andy the AGENT (right panel) across the pre- table-top, beginning, middle and end ECHOES sessions and the post- table-top session. Reference frequency of TD children initiations is represented as the red dashed line (the average proportion of responses over all five time periods) with $95 \%$ confidence intervals for the TD group represented as red dotted lines. Background coloured lines represent individual participant values at each session (anonymised IDs tally with Table 2).

group. The mean frequency of HUMAN initiations for the TD reference group is $3.1(S D=2.9)$ per 15-minute block, represented as a red dashed line in Figure 9 (95\% confidence intervals denoted by red dotted lines). By comparison, the frequency of initiations for the ASC group is higher than the TD reference across all five phases (independent-samples $t$-test reveal a significant difference at all phases, $p<0.05)$. This may not be as surprising as it first seems. The TD reference group are not IQ matched to the ASC group and as the ECHOES environment was designed for users with significantly less ability, the TD group found the learning activities easy and did not need to seek the help from, or make comments to the practitioner. Furthermore, in the pre- and post-table-top session, the TD children waited until they were instructed to do something by the practitioner, whereas the ASC children were often making off-task requests for interaction which, although not strictly pre-/post-test task related, could be seen as positive, given ECHOES' aim of increasing ASC children's bids for interaction.

The results of the analysis focusing on the frequency of initiations to HUMAN, illustrated in Figure 9 (left panel) by a black dashed dotted line, reveal that the ASC children make more initiations before and during ECHOES use than would normally be expected given the profile of this group. The mean frequency of HUMAN initiations for the TD reference group is 3.1 $(S D=2.9)$ per 15-minute block, represented as a red dashed line in Figure 9 (95\% confidence intervals denoted by red dotted lines). By comparison, the frequency of initiations for the ASC group is higher than the TD reference across all five phases (independent-samples $t$-test reveal a significant difference at all phases, $p<0.05)$. This may not be as surprising as it first seems. The TD reference group are 
not IQ matched to the ASC group and as the ECHOES environment was designed for users with significantly less ability, the TD group found the learning activities easy and did not need to seek the help from, or make comments to the practitioner. Furthermore, in the pre- and post-table-top session, the TD children waited until they were instructed to do something by the practitioner, whereas the ASC children were often making off-task requests for interaction which, although not strictly pre-/post-test task related, could be seen as positive, given ECHOES' aim of increasing ASC children's bids for interaction.

A repeated-measures ANOVA of initiation frequency does not show a significant effect of phase pre, beg, mid, end, post; $F(4,56)=1,341, p=0.266$ ) even though there is a numerical increase in initiations from pre ECHOES session (mean $=10.27, S D=8.1$ ) to end ECHOES session ( $m e a n=$ $17.9, S D=25.9)$. This increase does not reach significance due to large variance across children $(t(16)=-1.361, p=0.192)$. This, in turn, highlights (i) the heterogeneity within our ASC group (see the variable frequency of initiations across individual participants represented as the different colour lines in Figure 9 left panel) and (ii) the fact that some children may have benefited from ECHOES more than others.

In terms of children's initiations to the AGENT, we observe numerically fewer initiations than towards the HUMAN practitioner. However, this difference does not reach significance $(F(1,28)=$ 2.072, $p=0.161$, n.s.). Similar to the initiations to the HUMAN partner, the initiations to Andy also seem to be characterised by an increase over the course of the ECHOES sessions (Figure 9, right panel, black dashed line). ASC children show an increase from $4.89(S D=8.05)$ in the first session to $9.6(S D=13.7)$ in the final ECHOES session, however, this difference does not reach significance due to the large variance across individuals $(t(18)=-1.719, p=.103$, n.s.). For some ASC children, their comfort and interest in Andy may be increasing even though his interactivity is limited, e.g., the individual participant coloured lines above the black dashed group mean line in Figure 9, right panel. An increase in initiations towards the AGENT should be expected as a natural consequence of progressing through the ECHOES learning activities and moving on to the later activities that require turn-taking with Andy.

\section{DISCUSSION}

\subsection{Frequency of Initiations and Responses to Social Partners}

Our results show that as some of the children with ASC progress through the ECHOES environment (from beginning, middle and end), they seem to show corresponding numerical increases in initiations of joint-attentional behaviours to both the virtual character and the human practitioner. Arguably, this change may be considered clinically, if not statistically significant at the group level. This is in contrast to the pre- and post- non-ECHOES 'table top' measures of the children's initiations of joint attention. What is of particular note is that initiations have been argued to be the most difficult of all joint attentional behaviours for children with ASC (APA 2013). Here, the ECHOES environment seems to engender an increase in these behaviours in some ASC children compared to outside the ECHOES environment and, moreover, this change increases as the child spends more time with ECHOES.

With respect to responding to bids for interaction, the pattern is slightly more nuanced in that the children with ASC showed an increasing tendency to respond to their human partner over the course of the ECHOES sessions, but an overall lower level of responsiveness to the AI agent. One explanation for this may be that a child's response to the human partner could lead to continued reciprocal interaction, whereas a response to Andy could not, since Andy was not aware that the child had responded unless the response related to, and was expressed through, the touch actions recognisable by ECHOES. Another possible explanation might be that actually blending human 
and $\mathrm{AI}$ interaction allows children to ease into the situation, making them more open to engaging with the human over time, with the AI agent then transforming from the central interaction vehicle to an object around which the interaction and communication can be conducted with the human partner. Although other researchers have also shown that technology can enhance co-located human interaction (Farr et al. 2010; Holt and Yuill 2017), it is worth noting that, in each case, these study designs explicitly included more than one individual interacting with the technology at the same time, either as pairs (in the case of Holt and Yuill (2017)) or groups of individuals (in the case of Farr et al. (2010)). In contrast, ECHOES was designed to be used by individual children; hence, the fact that ECHOES seems to engender increased social interactions with human partners who are not, strictly speaking, interacting directly with the technology themselves is all the more striking.

The impact that different learning activities may have had on the initiations and responses of children with ASC should be considered. Although the complexity of tasks may have increased over time, some actions such as those involving objects may have necessitated little or no communication with a social partner. As these actions have not been counted as initiations, or responses, the increase in ASC children's initiations and responses cannot be explained by the nature of the activities alone. This conclusion is further supported by that fact that the TD children experienced roughly the same sequence of activities and showed little change over time relating to the increase in the complexity of activities undertaken. A more plausible explanation may be that some activities may be more likely to provoke more initiations or responses to a social partner than others. The impact of particular activities is something that has been proposed for further analysis by Alcorn (2016), who has also explored the features that may contribute to this. Another possible explanation might be that the children became familiar with the set-up, the technology and the researchers, which led to the decrease in their anxiety and an increase in their motivation to communicate with the social partners. However, given that we have taken special care to familiarise the children with all of the researchers prior to the intervention specifically to reduce children's anxiety (see Figure 6, Section 4 for the discussion of the procedure), it is less likely that the increase in initiations can be explained by the decrease in anxiety and rise in the familiarity of the set-up. If this were the case, then we would also expect significant improvements on the post-test, as by that point the children were very familiar with both the activities and the researchers. Such improvements at post-test were not observed.

\subsection{Evidence of Transfer and Impact on Schools}

Whilst post-test quantitative analysis suggests no evidence of transfer from the ECHOES environment to the table-top activities, it is possible that further analysis of other classroom and play contexts may have provided more supportive evidence. Although the table-top activities defined in this study were chosen carefully on the basis of existing literature and other similar empirical studies, they may not in fact correspond to children's typical activities. However, each practitioner/researcher working with a child using ECHOES was asked to keep a research diary in which observations of the child's behaviour and reactions to the system were recorded. At the sites where the practitioner was a 'support for learning', or classroom assistant based in the school, the research diary also charted any changes or improvements seen in the classroom. Qualitative data collected through these research diaries, as well as through observation, teacher reports and interviews, suggests that there is potential for transfer from ECHOES to the classroom environment.

Classroom assistants who sat in on ECHOES sessions reported that they were able to observe specific behaviours in some children that would not have been apparent without the ECHOES environment. This provided insights to children on an individual level. By having a focussed exploration environment, staff were able to observe children benefitting from success within an 
educational context, and in several cases transferring this to the classroom. Several examples are given here, for illustrative purposes as follows:

a. One child had consistently had difficulty in initiating the end phase of interactions or classroom work. Within ECHOES the signing gestures of the virtual character included 'my turn', 'your turn' and 'finished', accompanied by the corresponding phrases being spoken by Andy (the 'finished' sign was accompanied be the spoken phrase 'all done'). Following interactions with ECHOES, on several occasions and without being prompted, the child indicated to the researchers that he wished to finish working with ECHOES. The child continued to indicate completion in the class (i.e., outside of the ECHOES context), using a combination of verbalisation and signing, along with his prompt strip. This extended beyond the classroom, with examples provided by teachers of similar actions in the playground and outside of school. 'We were able to identify ... the signs he was giving and then how to support them.' (Class teacher). This new ability also resulted in the reduction in this child's stress levels, as reported by the teachers.

b. A child who initially appeared to be lacking in confidence and did not attempt to interact with the researchers became much more verbal, responding to researchers and even initiating conversations by the end of the study. For example, he initiated communication by waving to researchers across the playground and engaging in conversation with them about a book he was reading, elaborating on points of conversation and providing new information unprompted: this suggested a potential growth in confidence, both in his use of the system and his interactions with the researchers.

c. Another child began the study showing limited verbalisation and little acknowledgement of the researchers' presence. However, as he became more fascinated with the bubbles in the initial ECHOES activity, he began to request to return to this scenario. Initially these were short utterances, such as 'bubbles'; eventually these became complete sentences (supplemented by the prompt strip symbols) such as 'I want bubbles please'. This change was remarkable and with the researchers responding to these requests his challenging behaviours diminished considerably by the end of the study.

d. Two boys, who previously played basketball individually in the playground, started taking turns at throwing their basketball through the hoop. This occurred without any facilitation from school staff and was observed on a number of occasions both during and after the ECHOES study. This particular example of turn taking could be mapped to an activity in the ECHOES system where the child takes turns with Andy to throw balls through a cloud (to make them change colour).

e. A child who showed little awareness of the researchers initially began to verbalise his requests for his favourite scenarios (facilitated by a prompt strip). It was noticed that overexaggerated praise (clapping and cheering) had a much greater effect than feedback in the ECHOES system. The child began to verbalise much more frequently and his eye contact improved. The transfer of knowledge of the need for exaggerated praise to the classroom resulted in increased confidence in tasks such as writing or answering questions, greater awareness of his achievements, and attempts to repeat them and to share them with others. 'This is a boy that now expects us to give him a round of applause when he achieves it and what I loved about it is the interaction he then had with the adults ... wanted us all to clap'. $\left(\mathrm{SLA}^{13}\right)$.

\footnotetext{
${ }^{13}$ Support for Learning Assistant.
} 
In addition to the task-related initiations observed, there is anecdotal evidence in later sessions with ECHOES of additional initiations from several children who showed no initial interest in Andy, but who were later observed to greet Andy spontaneously through gestures as well as verbally, including waving and saying 'Hi Andy!' when he walked onto the screen. As noted earlier, such behaviours were very surprising to teachers and support workers within the schools, who believed many of the children in question to be non-communicative. One child started spontaneously greeting staff in the classroom. A number of teachers reported increased confidence in several children over the course of the research, both when interacting with ECHOES and in the classroom.

Further description and analysis of such qualitative data is outside the remit of this article. However, one issue which merits further investigation is the extent to which the positive qualitative outcomes can be attributed to the use of ECHOES, to the presence of technology more generally, or perhaps even to a combination of ECHOES and the changed and highly individualised context in which children found themselves. Individual comments from teachers suggest that the AI agent was a key factor for many children, for although they may have not consistently interacted with him, they nevertheless 'bought into' him as a character. Further work, some of which has already begun (e.g., Porayska-Pomsta et al. (2013); see also Section 8), will focus on developing and manipulating the agent technology and will serve to illuminate any evidence in relation to the role that agents may play in provoking ASC children to engage in social communication and interaction.

In relation to the impact on schools, teachers benefited from first-hand experience of doing research and of seeing some children in a different light, discovering hidden abilities and potential of children in the context of their using ECHOES. This allowed the teachers to appreciate further the need for supporting children through different needs and the potential of technology in providing such support. Observing the individual children behaving more spontaneously and communicatively in the context of ECHOES than in the classroom was reported by teachers as the key aspect of the ECHOES environment.

Teachers' testimonies highlight their perspective on the research impact, in terms of three categories:

(1) Impact on children's communication: 'The [ECHOES] technology has a massive impact on children involved [...], it enabled them to communicate and succeed without any barriers or feeling constrained by everyday teaching. They were actually free to explore and learn and develop by themselves, which was absolutely fascinating to see [...] especially with children with very poor communication skills'. (Head Teacher, mainstream primary school.)

(2) Impact on school practices and training of teachers: '[ECHOES] inspired the school to look how that technology and pedagogy of learning can help all children who have communication difficulties and in fact all children'. (Head Teacher, special school.)

'I have learned such an awful lot [...]. I can take what I have seen to other areas in the school [...] that will help me do my job better'. (SLA, special school.)

(3) Impact on the school's and children's aspirations: 'As a result of that the school has really high aspirations for children, so it helps the school and the children develop their own understanding of what learning is'. (Head Teacher, special school.)

An unexpected impact was teachers' enthusiasm for continuing the involvement in further research, despite disruption and additional demands imposed on them. At least three schools are still involved in collaboration with individual ECHOES partners on both funded and student projects (see Section 8). A plausible explanation for this might lie in the openness of the communication between researchers and teachers, involving teachers in the decision making in relation to the 
studies (which children should participate, when and how) as well as giving them an active voice in the design of the environment itself throughout the research. Furthermore, the fact that ECHOES provided teachers with an environment in which they could witness children's previously unseen skills and abilities may also have led to their desire to continue to use ECHOES as a component in the broader learning context.

\subsection{Features of ECHOES: Lessons Learned}

Overall, the use of technology, especially of the AI agent, in the realm of ASC is promising. Within the literature there is a focus on transferring skills from the technology environment to practical settings (Rao et al. 2008), which represents an established challenge in ASC (Pole and Morrison 2003). Despite such transfer not always taking place in practice (Reynhout and Carter 2009), there are a number of successful cases (Scattone et al. 2006), who used structured observations to determine the extent of generalisation after using Social Stories (Gray and Garand 1993) to enhance social communication skills. While the extent of generalisation is difficult to measure in a meaningful way due to the small number of participants involved in those studies, the use of observations as a measure of success is encouraging. We believe that the ECHOES study presented in this article contributes further to the collective knowledge of the types of technologies and their specific uses in classroom contexts, especially those involving blended AI and human interaction, that may bring real benefits to children with ASC, and of the methods for gathering evidence of the efficacy of such approaches.

ECHOES was designed to provide a child-centred environment that encourages exploration and play. Children with ASC were seen to engage with ECHOES, and to interact with the virtual character and the objects therein. As discussed in Section 2.1, during the formative evaluation of the environment, older children with ASC commented on their likes and dislikes, and suggested improvements. A number of design iterations, with input from children, teachers and others with expertise in designing technology for children with ASC, ensured that the resulting environment was engaging and well matched to the target audience of young children with ASC. The data collected demonstrated that the children did engage and interact with the AI agent by addressing comments and questions to Andy, and initiating social communication with him. For example, when Andy failed to put a coloured ball in the matching box, children would often prompt him directly, e.g., by pointing to indicate the correct box. Multiple examples of evidence were collected showing children socially communicating with the virtual character.

The learning activities, delivered through game play, served to provide an environment in which there were many opportunities for children to engage in spontaneous communication behaviours. The approach adopted through the design of the environment of stimulating and prompting interaction appears to be a productive one, and an alternative to interventions in which the locus of control is with the practitioners/adult rather than with the child.

The evidence-based approach, in this case derived from SCERTS, provided an informed basis for the design of learning activities, and for later analysis of the children's social communication behaviours. As SCERTS is also an approach used in a number of schools in the UK and elsewhere, this means that environments such as ECHOES can be integrated into the wider curriculum of the school, and be directly related to specific learning goals and support for each child, regardless of the wide range of individual needs.

The design, formative, and efficacy evaluation stages of the ECHOES project were conducted in schools, rather than laboratories. This required an approach that was carefully planned and orchestrated in consultation and collaboration with schools and teachers, including additional time for classroom observation and familiarisation activities between children and researchers, targeted training of both researchers and practitioners, and flexibility in the final evaluation studies to 
accommodate the needs of individual children and the specific schools' contexts. Although this meant that the exact conditions of the evaluation study differed across sites (e.g., smaller rooms meant that social partner position in relation to the child varied), children engaged with ECHOES and communicated socially with both human and virtual partners at all sites.

In relation to the approach taken in ECHOES, a major requirement was that the environment should be suitable for use by children with ASC who may also have learning difficulties and limited language abilities. Children with ASC and without intellectual difficulties have more frequently been the target of interventions (Fletcher-Watson et al. 2016), but, arguably, may not have as great a need as those described as so-called 'low functioning'. Although in the analysis presented in this article all ASC children are considered together, a future analysis that distinguishes between children based on their intellectual development may reveal greater gains for the latter group.

Children both with and without learning difficulties successfully engaged with ECHOES. In addition to those children whose data was reported in this article, a number of other children participated in our studies. ${ }^{14}$ This included a number of children with very little language and who typically found it difficult to participate in other classroom activities. For all children, sessions with ECHOES were included in their regular (and familiar) classroom schedule planners. On the whole, they participated eagerly in these sessions. In a number of cases they were accompanied by teaching assistants who worked specifically with them. In many cases the teaching assistants commented on their surprise at how much the children were able to do within ECHOES. This was reinforced by observations of classroom teachers, when shown videos of the children demonstrating spontaneous communication behaviours when interacting with ECHOES. The abilities of children with ASC described as 'low functioning', and their potential for engaging in communication with others, should not be underestimated.

A major feature of ECHOES, arising from earlier studies (Alcorn et al. 2011), was that it was designed to include the practitioner/researcher as a social partner for the child, in addition to the AI agent. This provided many opportunities for social communication that were frequently taken up throughout the sessions. This demonstrates the potential for technology such as ECHOES to serve as the object of social communication, and as a stimulus or catalyst for spontaneous communication behaviours, as well as (rather than exclusively) an environment within which social interaction can take place. The role of the human partner should be considered further when developing AI technology, and arguably other forms of technology, for use by children with ASC in relation to social communication. The role of the human partner should be explicitly considered, both in the design and evaluation phases, and also in the intended context of use.

\subsection{Reflections on the ECHOES' Evaluation Methodology: Efficacy vs. Effectiveness}

In evaluating ECHOES, we framed our findings in terms of the following two important and related societal questions concerning ASC: (i) optimal outcome (Suh et al. 2016), often considered to equate to recovery from autism, and (ii) neuro-diversity. Traditionally, optimal outcomes are sought in intervention studies by looking for pre-/post-test differences (Salkind 2010). Here, we offer an alternative way of framing the question of optimal outcome, not in terms of recovering from autism, but in terms of changing the environment and finding associated changes in performance and behaviour. This is arguably something that any technology-based intervention is suited to, given the specific and precise nature of its development and potential for fine-grained data on how specific changes in the environment might lead to concomitant changes in users' behaviours and performance. We argue that this reframing has two benefits. First, it forces us to look at the process of any change, rather than looking for high level differences (which can be hard to

\footnotetext{
${ }^{14}$ As mentioned in Section 4.1, where there was insufficient data for children, they were excluded from the analysis.
} 
measure and even harder to show changes in). Second, it means that we have the potential to include more children in our evaluation rather than creating inclusion/exclusion criteria (based on group matching), which might result in fewer children participating in studies.

Rao et al. 2008 argued that before interventions are rolled out into large-scale randomised control trials (in essence, trials that are focused on ascertaining effectiveness), smaller scale efficacy studies should be done to demonstrate their potential. We argue that our evaluation resides at a 'pre-efficacy' stage, in which we believe that ECHOES shows promise in that children with both autism and intellectual difficulties engage with the environment, interact with the AI agent and with a human partner, progress through different learning activities and seem to change their behaviour whilst in the environment. However, our results are tempered with caution, given the lack of a direct comparison group (e.g., an ASC wait-list control). Our findings suggest, though, that the type of technology-based intervention adopted in the ECHOES project may result in real behaviour change, even if it is limited to the ECHOES environment. More recent research based on ECHOES by Alcorn 2016 provides supporting evidence for these conclusions.

Generalisation and ascertaining whether generalisation is maintained on follow-up has been considered to be the 'holy grail' of intervention studies in ASC (Rajendran 2013). However, our results suggest that another way to reframe the question may be to ask what it is about a particular environment (in this case, the ECHOES environment) that brings about change within that context. If neuro-diversity is the acceptance of people who are neuro-atypical, then these environmental clues may be immensely valuable if we seek to fit the environment to the person, rather than the other way round (Rajendran 2013).

However, such an approach raises questions that are also key to the ongoing debate within evidence-based practice in education as to what constitutes (or should constitute) 'good' evidence in educational research (see, e.g., (Biesta 2007, 2013)). This debate highlights a tension between the need to generate evidence that can be trusted, and is on par with the evidence emerging from the biological sciences (and indeed using the same methods (Guldberg 2017; US National Research Council 2002)), and the realities of live classroom environments, where the focus is on individual children's needs, on fine grained changes in their behaviour, and on the front-line practitioners' ability to spontaneously adapt in pedagogically beneficial ways to often unexpected classroom/ learning events (Guldberg et al. 2017; Reichow et al. 2008; Stahmer et al. 2011). The idiosyncratic nature of autism adds to the challenge of reconciling the need to understand the individual child in the context of specific environments and situations, and the desire to generalise the intervention approaches used along with any evidence of their success. On the whole, 'hard' evidence, i.e., that which is typically generated through randomised control trials, seldom infiltrates real classroom practice, not least because interventions that are tightly controlled in the clinical or lab environments are notoriously hard to replicate by clinically untrained front-line practitioners in often messy and only partly predictable classroom settings (Dingfelder and Mandell 2011; Parsons et al. 2013; Porayska-Pomsta 2016).

\section{CONCLUSIONS AND FURTHER DIRECTIONS FOR RESEARCH}

This article presented an evaluation of the ECHOES technology-based intervention, which aimed to ascertain its potential to facilitate autistic children's ability to engage in social interaction. The evaluation was conducted in several schools across the UK, and focused on working with the socalled 'low functioning' autistic children across the 4-14 age range. The results of the evaluation showed a significant increase in the proportion of children's responses to the human social partners, and suggested positive trends with respect to children's initiations to both social partners (an $\mathrm{AI}$ agent and a human practitioner). These results are very encouraging in their own right. However, we also believe that the results highlight a number of important considerations for further 
research directions in the area of technology for autism education, and on the role that technology, especially AI-based technology, may play in helping us understand and respond to children with ASC, and in informing technology-enhanced educational practices more broadly.

A key aspect of the approach presented in this article was the way in which the intervention was implemented in the different school contexts, placing an emphasis on ecological validity in assessing the educational efficacy of the ECHOES approach, as well as on the need for flexibility in the way that the AI technology's role is prioritised and understood by the practitioners and researchers. Specifically, an over-reliance on technological support alone may be misguided in autism related practices and, arguably, in broader educational contexts as well, where it can lead to many important opportunities for learning being either ignored or missed altogether. In ECHOES, allowing a human practitioner to provide social partnership on demand alongside the AI agent has led to the following: (i) the revelation and enhancement of many individual children's specific abilities, (ii) consideration of how research and educational practice may be consolidated, and (iii) rethinking of how technology may be designed to perform an optimal role in supporting both the learners and educational practitioners in achieving the desired learning outcomes. Teachers who participated in the research were able to tailor their classroom support to the individual children based on their newfound understanding of what the children could do, rather than on what the children had revealed about themselves to date in typical classroom situations.

However, there are limitations associated with the study, many of which are artefacts of working in the context of autism - a condition characterised by high individual heterogeneity and comorbidity with other developmental conditions. These limitations include the fact that, although a relatively large number of participants took part in this research as compared to other studies involving autistic children, the number coupled with the idiosyncratic differences between the individual participants means that the results may not generalise to all contexts and all individuals beyond this research. Furthermore, as indicated throughout the article, the lack of a comparable control group and activities means that the conclusions drawn from this research apply mainly to within-the-environment improvements. These limitations are being addressed in further work, some of which has already began or has been undertaken.

Since the completion of the ECHOES project, many of the insights gained have served to inspire new ways of thinking by both the individual ECHOES researchers and by the teachers who were involved in ECHOES, with several schools having become long-term partners in ongoing research. For example, the SHAPE project (Guldberg et al. 2017; Parsons et al. 2015) focused explicitly on the challenge of bridging between research goals and outcomes, and school needs and practices. SHAPE investigated how different technologies developed for children with ASC may be embedded in different schools' everyday practices to reveal any mismatches and commonalities in teachers' vs. researchers' perspectives vis-á-vis what children might actually find inspiring, motivating and useful, and to highlight any opportunities for pedagogical and technological innovation. This focus was further extended in another project, SHARE-IT (Porayska-Pomsta et al. 2013), which aimed to sustainably include the perspectives of all stakeholders concerned (parents, teachers, researchers and children), for example through allowing the teachers and the parents to (re-)configure both the children's profiles and the specific activities within the environment, thus supporting the construction and periodic modification of the (user) child models underpinning the system's interactions with the children. SHARE-IT's focus reflected the insights gained via the ECHOES project, specifically - the need to increase the range and variability of the learning activities and provide more customisable and malleable technologies in terms of their designs and deployment in different contexts. Crucially, through its further investment in the planning technology that underpinned the ECHOES agent's behaviours, SHARE-IT also aimed to respond explicitly to the debate that was on-going within the ECHOES project with respect to the degree 
and the nature of artificial intelligence that was actually needed to provide the necessary support. Although SHARE-IT resulted in a much more socially able AI agent than was achieved during ECHOES, this debate is still on-going and the questions it raises remain open.

Post-ECHOES and the projects that follow from it, it is clear that there is a need for balance between technological innovation push and the educational needs pull to allow us to consider how technology may be employed optimally in the context of autism-focused education. There is a definitive need for flexibility in the way that the respective roles of technology and human social partners are understood and managed, with the best-case scenario, i.e., one that serves the learning process, being that technology and the human practitioner enhance, rather than override, each other. The question of flexibility of the environment within which children are motivated to spontaneously engage in social interaction with others and the specific opportunities that technology provides with respect to supporting children in doing so was the subject of a Ph.D. thesis by Alcorn (2016) which was inspired by the ECHOES project and which utilised its data as a starting point. Alcorn's investigation focused on the motivational potential of subjectively inconsistent (i.e., discrepant, unintentional and non-designed) aspects in game-like virtual contexts for young children with ASC. Her analysis of the ECHOES video data illustrated that a heterogeneous group of children all reacted frequently and socially to naturally occurring discrepant aspects within ECHOES. This led to the creation of a set of high-level design principles that might facilitate similar patterns of spontaneous, positive initiations around discrepancies. These design principles were implemented in a set of new touch-screen games that sought to establish, and then deliberately violate, child expectations. The results of Alcorn's research suggest that it is possible to motivate children's communication - specifically their initiations - by including deliberately designed discrepancies in the technology.

While the interdisciplinary nature of the ECHOES project presented the team with many intellectual challenges, it also offered a richness of insight that is now bearing fruit in many follow-on projects as just illustrated. The ECHOES project and the outcome of the use of ECHOES technology as reported in this article contributed to a change in the team's perception, not only of what is technologically possible, but also of what needs to be approached with an open mind. In particular, if the support offered is to go beyond paying lip service to the question of neuro-diversity and inclusion, there is a need for balance between technology, in this case AI technology, and the human role in delivering support to the child, and in moulding the learning environment to the needs of individual children. We believe that the results presented in this article, along with the way that the ECHOES technology was designed and deployed, provide an evidence-based starting point for challenging and addressing the existing orthodoxies in relation to the perceived and real potential of AI technology for autism education and research.

\section{ACKNOWLEDGMENTS}

We would like to thank all the participating schools, including children, teachers and parents, Michael Anderson for providing the voice of the AI agent, as well as TLRP-TEL programme director Prof. Richard Noss for his invaluable advice and encouragement throughout the project.

In memory of Prof fon Oberlander (1962-2017)

\section{REFERENCES}

B. Abirached, Y. Zhang, J. Aggarwal, B. Tamersoy, T. Fernandes, J. Miranda, and V. Orvalho. 2009. Improving communication skills of children with ASDs through interaction with virtual characters. In Proceedings of the IEEE 1st International Conference on Serious Games and Applications for Health (SeGAH). 1-4.

A. Alcorn, H. Pain, G. Rajendran, T. Smith, O. Lemon, K. Porayska-Pomsta, M. E. Foster, K. Avramides, C. Frauenberger, and S. Bernardini. 2011. Social communication between virtual characters and children with autism. In Proceedings of the 15th International Conference on Artificial Intelligence in Education (AIED’11). Springer-Verlag, Berlin, 7-14. 
A. M. Alcorn. 2016. Embedding novel and surprising elements in touch-screen games for children with autism: creating experiences 'worth communicating about'. Ph.D. Dissertation. University of Edinburgh, Edinburgh, Scotland.

K. Anderson, E. André, T. Baur, S. Bernardini, M. Chollet, E. Chryssafidou, I. Damian, C. Ennis, A. Egges, P. Gebhard, H. Jones, M. Ochs, C. Pelachaud, K. Porayska-Pomsta, P. Rizzo, and N. Sabouret. 2013. The TARDIS framework: Intelligent virtual agents for social coaching in job interviews. In Advances in Computer Entertainment. Springer, 476-491.

A. Anwar, M. Rahman, S. Ferdous, S. Anik, and S. Ahmed. 2011. AA computer game based approach for increasing fluency in the speech of the autistic children. In Proceedings of the 11th IEEE International Conference on Advanced Learning Technologies (ICALT'11). 17-18.

APA. 2013. Diagnostic and Statistical Manual of Mental Disorders, Fifth Edition, Text Revision (DSM-5). American Psychiatric Association.

R. Aylett, N. Vannini, E. Andre, A. Paiva, S. Enz, and L. Hall. 2009. But it was another country: Agents and intercultural empathy. In Proceedings of the 8th International Conference on Autonomous Agents and Multiagent Systems (I/International Foundation for Autonomous Agents and Multiagent Systems.). Vol. 1, 329-336.

R. S. Baker. 2016. Stupid tutoring systems, intelligent humans.International fournal of Artificial Intelligence in Education 26, 2 (2016), 600-614.

E. Barakova, G. van Wanrooij, R. van Limpt, and M. Menting. 2007. Using an emergent system concept in designing interactive games for autistic children. In Proceedings of the 6th International Conference on Interaction Design and Children. (IDC'07). ACM, 73-76.

L. Barnard-Brak, A. Brewer, S. Chesnut, D. Richman, and A. M. Schaeffer. 2016. The sensitivity and specificity of the social communication questionnaire for autism spectrum with respect to age. Autism Research 9, 8 (2016), 838-845.

L. Bartoli, C. Corradi, F. Garzotto, and M. Valoriani. 2013. Exploring motion-based touchless games for autistic children?s learning. In Proceedings of the ACM Interaction Design and Children Conference (IDC'13). ACM, New York.

A. Battocchi, F. Pianesi, D. Tomasini, M. Zancanaro, G. Esposito, P. Venuti, A. Ben Sasson, E. Gal, and P. L. Weiss. 2013. Collaborative puzzle game: A tabletop interactive game for fostering collaboration in children with autism spectrum disorders (ASD). In Proceedings of the ACM International Conference on Interactive Tabletops and Surfaces (ITS'09). ACM, 197-204.

N. Bauminger. 2002. The facilitation of social-emotional understanding and social interaction in high-functioning children with autism: Intervention outcomes. fournal of Autism and Developmental Disorders 32 (2002), 283-298.

R. Beaumont and K. Sofronoff. 2008. A multi-component social skills intervention for children with asperger syndrome: The junior detective training program. fournal of Child Psychology and Psychiatry 49 (2008), 743-753.

S. Bernardini and K. Porayska-Pomsta. 2013. Planning-based social partners for children with autism. In Proceedings of the Twenty Third International Conference on Automated Planning and Scheduling (ICAPS-13). AAAI Press, Rome, Itay.

S. Bernardini, K. Porayska-Pomsta, and Smith T. J. 2014. Echoes: An intelligent serious game for fostering social communication in children with autism. Information Sciences 264 (2014), 41-60.

G. Biesta. 2007. Why "what works" won't work: Evidence-based practice and the democratic deficit in educational research.Educational Theory 57, 1 (2007), 1-22.

G. Biesta. 2013. The Beautiful Risk of Education. Boulder and London: Paradigm Publishers.

A. Bosseler and D. Massaro. 2003. Development and evaluation of a computer- animated tutor for vocabulary and language learning in children with autism. Ifournal of Autism and Developmental Disorders 33, 6 (2003), 653-672.

M. O. Cavazza, F. Charles, and S. J. Mead. 2002. Character-based interactive storytelling. IEEE Intelligent Systems 17, 4 (2002), $17-24$.

H.-M. Chiang and M. Carter. 2008. Spontaneity of communication in individuals with autism. fournal of Autism and Developmental Disorders 38, 4 (2008), 693-705.

S. Cobb. 2007. Virtual environments supporting learning and communication in special needs education. Topics in Language Disorders 27, 3 (2007), 211-225.

Mihaly Csikszentmihalyi. 1991. Flow: The Psychology of Optimal Experience. Harper Perennial, New York, NY. Retrieved from http://www.amazon.com/gp/product/0060920432/ref=si3_rdr_bb_product/104-4616565-4570345

K. Dautenhahn and I. Werry. 2004. Towards interactive robots in autism therapy: Background, motivation and challenges. Pragmatics and Cognition 12, 1 (2004), 1-35.

M. Dennis, D. J. Francis, P. T. Cirino, R. Schachar, M. A. Barnes, and J. M. Fletcher. 2009. Why IQ is not a covariate in cognitive studies of neurodevelopmental disorders. Journal of the International Neuropsychological Society 15, 3 (2009), 331-343.

J. Dewey. 1998. Experience and Nature. Dover Publications Inc.

J. Dias and A. Paiva. 2005. Feeling and reasoning: A computational model for emotional characters. In Progress in Artificial Intelligence. Lecture Notes in Computer Science, vol. 3808. Springer Berlin, Heidelberg, 127-140.

H. E. Dingfelder and D. S. Mandell. 2011. Bridging the research-to-practice gap: An application of diffusion of innovation theory. Journal of Autism and Developmental Disorders 41, 5 (2011), 597-609. DOI: https://doi.org/10.1007/ s10803-010-1081-0 
W. Farr, N. Yuill, and H. Raffle. 2010. Social benefits of a tangible user interface for children with autistic spectrum conditions. Autism 14, 3 (2010), 237-252.

S. L. Finkelstein, A. Nickel, L. Harrison, E. A. Suma, and T. Barnes. 2009. cMotion: A new game design to teach emotion recognition and programming logic to children using virtual humans. In Proceedings of the 2009 IEEE Virtual Reality Conference. 249-250.

S. Fletcher-Watson. 2014. A targeted review of computer-assisted learning for people with autism spectrum disorder: Towards a consistent methodology. Review fournal of Autism and Developmental Disorders 1, 2 (2014), 87-100.

S. Fletcher-Watson, H. Pain, S. Hammond, A. Humphry, and H. McConachie. 2016. Designing for young children with autism spectrum disorder: A case study of an iPad app. International fournal of Child-Computer Interaction 7 (2016), $1-14$.

M. E. Foster, K. Avramides, S. Bernardini, J. Chen, C. Frauenberger, O. Lemon, and K. Porayska-Pomsta. 2010. Supporting children?s social communication skills through interactive narratives with virtual characters. In Proceedings of ACM Multimedia. ACM, Florence, Italy.

C. Frauenberger, J. Good, A. Alcorn, and H. Pain. 2013. Conversing through and about technologies: Design critique as an opportunity to engage children with autism and broaden research(er) perspectives. International fournal of ChildComputer Interaction 1, 2 (2013), 38-49.

C. Frauenberger, J. Good, and W. Keay-Bright. 2010. Phenomenology, a framework for participatory design. In Proceedings of the 11th Biennial Participatory Design Conference (PDC'10). ACM, New York, NY, 187-190.

C. Frauenberger, J. Good, and W. Keay-Bright. 2011. Designing technology for children with special needs: Bridging perspectives through participatory design. CoDesign 7, 1 (2011), 1-28.

O. Golan, E. Ashwin, Y. Granader, S. McClintock, K. Day, V. Leggett, and S. Baron-Cohen. 2010. A multi-component social skills intervention for children with asperger syndrome: The junior detective training program. fournal of Autism and Developmental Disorders 40 (2010), 269-279.

M. Goodwin. 2008. Enhancing and accelerating the pace of autism research and treatment: The promise of developing innovative technology. Focus on Autism and Other Developmental Disabilities 23, 2 (2008).

C. Gray and J. Garand. 1993. Social stories: Improving responses of students with autism with accurate social information. Focus on Autism and Other Developmental Disabilities 8, 1 (1993), 1-10.

O. Grynszpan, J.-C. Martin, and J. Nadel. 2008. Multimedia interfaces for users with high functioning autism: An empirical investigation. International fournal on Human-Computer Studies 66, 8 (2008), 628-639.

O. Grynszpan, P. L. T. Weiss, F. Perez-Diaz, and E. Gal. 2014. Innovative technology-based interventions for autism spectrum disorders: A meta-analysis. Autism 18, 4 (2014), 851-871.

K. Guldberg. 2017. Evidence based practice in autism educational research: Can we bridge the research and practice gap? Oxford Review of Education 43, 4 (2017).

K. Guldberg, S. Parsons, K. Porayska-Pomsta, and W. Keay-Bright. 2017. Challenging the knowledge transfer orthodoxy: Knowledge co-construction in technology enhanced learning for children with autism. British Educational Research fournal 43, 2 (2017), 384-413.

M. Hauck, D. Fein, L. Waterhouse, and C. Feinstein. 1995. Social initiations by autistic children to adults and other children. fournal of Autism and Developmental Disorders 25 (1995), 579-595.

G. Herrera, F. Alcantud, R. Jordan, A. Blanquer, G. Labajo, and C. De Pablo. 2008. Development of symbolic play through the use of virtual reality tools for children with autism spectrum disorders. Two case studies. Sage Publications and The National Autistic Society 12, 2 (2008), 143-157. DOI: https://doi.org/10.1177/1362361307086657

G. Herrera, Casas X., J. Sevilla, L. Rosa, C. Pardo, J. Plaza, R. Jordan, and S. Le Groux. 2012. Pictogram room: Natural interaction technologies to aid in the development of children with autism. Annuary of Clinical and Health Psychology 8 (2012), 39-44.

S. Holt and N. Yuill. 2017. Tablets for two: How dual tablets can facilitate other-awareness and communication in learning disabled children with autism. International fournal of Child-Computer Interaction 11 (2017), 72-82.

I. M. Hopkins, M. W. Gower, T. A. Perez, D. S. Smith, F. R. Amthor, and et al. 2011. Avatar assistant: Improving social skills in students with an ASD through a computer-based intervention. Fournal of Autism and Developmental Disorders 41, 11 (2011), 1543-1555.

J. P. Hourcade, S. R. Williams, E. A. Miller, K. E. Huebner, and L. J. Liang. 2013. Evaluation of tablet apps to encourage social interaction in children with autism spectrum disorders. In Proceedings of the SIGCHI Conference on Human Factors in Computing Systems (CHI'13). ACM, New York, 3197-3206.

N. Kandalaft, M. R. Didehbani, D. C. Krawczyk, T. T. Allen, and S. B. Chapman. 2013. Virtual reality social cognition training for young adults with high-functioning autism, journal of autism and developmental disorders. fournal of Autism and Developmental Disorders 43, 1 (2013), 34-44.

P. Kenny, H. Arno, J. Gratch, W. Swartout, D. R. Traum, S. Marsella, and D. Piepol. 2007. Building interactive virtual humans for training environments. In Proceedings of the Interservice/Industry Training, Simulation, and Education Conference (I/ITSEC). 
H. Kozima, M. Michalowski, and C. Nakagawa. 2009. Keepon: A playful robot for research, therapy, and entertainment. International fournal of Social Robotics 1, 1 (2009), 3-18.

C. Lord, M. Rutter, P. DiLavore, S. Risi, K. Gotham, and S. Bishop. 2012. Autism Diagnostic Observation Schedule: ADOS-2. Western Psychological Services Torrance.

L. Malinverni, J. Mora, V. Padillo, A. Hervas, and N. Pares. 2014. Pico?s adventure: A kinect game to promote social initiation in children with autism spectrum disorder. In Proceedings of the ITASD International Conference (IDC'16). ACM, Paris, France.

D. Massaro. 2006. Embodied agents in language learning for children with language challenges. In Proceedings of the 10th International Conference on Computers Helping People with Special Needs. (ICCHP?06). Springer-Verlag, Berlin, Heidelberg, 809-816.

J. Mora-Guiard, C. Crowell, N. Pares, and Heaton. P. 2016. Lands of fog: Helping children with autism in social interaction through full-body interactive experience. In Proceedings of the ACM Interaction Design and Children Conference (IDC'16). ACM, Manchester, UK.

L. Mottron. 2004. Matching strategies in cognitive research with individuals with high-functioning autism: Current practices, instrument biases, and recommendations. Journal of Autism and Developmental Disorders 34, 1 (2004), 19-27.

P. Mundy, C. Delgado, J. Block, M. Venezia, A. Hogan, and J. Seibert. 2003. Early Social Communication Scales. University of Miami, Coral Gables, FL.

NAS 2016. What is autism? Retrieved November 12, 2016 from http://www.autism.org.uk/about/what-is.aspx.

A. Ortony, G L. Clore, and A. Collins. 1988. The Cognitive Structure of Emotions. Cambridge University Press.

S. Parsons, T. Charman, R. Faulkner, J. Ragan, S. Wallace, and K. Wittemeyer. 2013. Commentary? bridging the research and practice gap in autism: The importance of creating research partnerships with schools. Autism 17, 3 (2013), 268-280.

S. Parsons and S. Cobb. 2011. State-of-the-art of virtual reality technologies for children on the autism spectrum. European Journal of Special Needs Education 26, 3 (2011), 355-366.

S. Parsons, K. Guldberg, A. MacLeod, G. Jones, A. Prunty, and T. Balfe. 2007. International review of the evidence on best practice in educational provision for children on the autism spectrum. European fournal of Special Needs Education 26, 1 (2007), 47-63.

S. Parsons, K. Guldberg, K. Porayska-Pomsta, and R. Lee. 2015. Digital stories as a method for evidence-based practice and knowledge co-creation in technology-enhanced learning for children with autism. International fournal of Research and Method in Education 38, 3 (2015), 247-271. DOI: https://doi.org/10.1080/1743727X.2015.1019852

S. Parsons and P. Mitchell. 2017. The potential of virtual reality in social skills training for people with autistic spectrum disorders. Journal of Intellectual Disability Research 46, 5 (2017), 430-443.

R. C. Pennington. 2010. Computer-assisted instruction for teaching academic skills to students with autism spectrum disorders: A review of literature. Focus on Autism and Other Developmental Disabilities 25, 1 (2010), 239-248.

C. Pole and M. Morrison. 2003. Ethnography for Education. Open University Press.

K. Porayska-Pomsta. 2016. AI as a methodology for supporting educational praxis and teachers? Metacognition. International fournal of Artificial Intelligence in Education 26, 2 (2016), 679-700.

K. Porayska-Pomsta, K. Anderson, S. Bernardini, K. Guldberg, T. Smith, L. Kossivaki, S. Hodgings, and I. Lowe. 2013. Building and an intelligent, authorable serious game for autistic children and their carers. In Advances in Computer Entertainment. Springer, Cham, 456-475.

K. Porayska-Pomsta, C. Frauenberger, H. Pain, G. Rajendran, T. Smith, R. Menzies, M. E. Foster, A. Alcorn, S. Wass, S. Bernardini, K. Avramides, W. Keay-Bright, J. Chen, A. Waller, K. Guldberg, J. Good, and O. Lemon. 2011. Developing technology for autism: An interdisciplinary approach. Personal Ubiquitous Compututing 16, 2 (Feb. 2011), 117-127.

B. M. Prizant, A. M. Wetherby, E. Rubin, and A. C. Laurent. 2003. The SCERTS model: A transactional, family-centered approach to enhancing communication and socioemotional ability in children with autism spectrum disorder. Infants and Young Children 16, 4 (2003), 296-316.

B.M. Prizant, A.M. Wetherby, E. Rubin, A.C. Laurent, and P.J. Rydell. 2006. The SCERTS® Model: A Comprehensive Educational Approach for Children with Autism Spectrum Disorders. Brookes.

M. M. Rahman, S. Ferdous, S. I. Ahmed, and A. Anwar. 2011. Speech development of autistic children by interactive computer games. Interactive Technology and Smart Education 8, 4 (2011), 208-223.

G. Rajendran. 2013. Virtual environments and autism: A developmental psychopathological approach. fournal of Computer Assisted Learning 29, 4 (2013), 334-347. DOI: https://doi.org/10.1111/jcal.12006

S. Ramdoss, R. Lang, A. Mulloy, J. Franco, M. O’Reilly, R. Didden, and G. Lancioni. 2011a. Use of computer-based interventions to teach communication skills to children with autism spectrum disorders: A systematic review. Fournal of Behavioral Education 20, 1 (2011), 55-76.

S. Ramdoss, A. Mulloy, R. Lang, M. O’Reilly, J. Sigafoos, and et al. Lancioni, G.2011b. Use of computer-based interventions to improve literacy skills in students with autism spectrum disorders: A systematic review. Research in Autism Spectrum Disorders 5, 4 (2011), 1306-1318. 
P. A. Rao, D. C. Beidel, and M. J. Murray. 2008. Character-based interactive storytelling. fournal of Autism and Developmental Disorders 38, 2 (Feb. 2008), 353-361.

V. S. Rao, V. Raman, and A. V. Mysore. 2015. Issues related to obtaining intelligence quotient-matched controls in autism research. Indian fournal of Psychological Medicine 37, 2 (2015), 149.

B. Reichow, F. R. Volkmar, and D. V. Chiccetti. 2008. Development of the evaluative method for evaluating and determining evidence-based practices in autism. Journal of Autism and Developmental Disorders 38 (2008), 1311-1319.

G. Reynhout and M. Carter. 2009. The use of social stories by teachers and their perceived efficacy. Research in Autism Spectrum Disorders 3, 1 (2009), 232-251.

S. J. Russell and P. Norvig. 2003. Artificial Intelligence: A Modern Approach (2nd ed.) Prentice Hall.

N. J. Salkind. 2010. Encyclopedia of Research Design. Sage Research Methods.

D. Scattone, D. H. Tingstrom, and S. M. Wilczynski. 2006. Increasing appropriate social interactions of children with autism spectrum disorders using social StoriesTM. Focus on Autism and Other Developmental Disabilities 21, 4 (2006), 211-222.

B. Schuller, E. Marchi, S. Baron-Cohen, H. OReilly, P. Robinson, I. Davies, O. Golan, S. Friedenson, S. Tal, S. Newman, N. Meir, R. Shillo, A. Camurri, S. Piana, S. Blte, D. Lundqvist, B. Berggren, S. A., and N. Sullings. 2013. IASC-inclusion: Interactive emotion games for social inclusion of children with autism spectrum conditions. In Proceedings 1st International Workshop on Intelligent Digital Games for Empowerment and Inclusion (IDGEI'13).

C. A. Smith and R. S. Lazarus. 1990. Emotion and adaptation. In Handbook of Personality: Theory and Research. I. Vlahavas, D. Vrakas, and L.A. Pervin (Eds.). Guilford, New York, Chapter 23, 609-637.

A. C. Stahmer, L. Schreimban, and A. B. Cunningham. 2011. Toward a technology of treatment individualization for young children with autism spectrum disorders. Brain Research 1380 (2011), 229-239.

D. C. Strickland, D. McAllister, C. D. Coles, and S. Osborne. 2007. An evolution of virtual reality training designs for children with autism and fetal alcohol spectrum disorders. Topics in Language Disorders 27, 3 (2007), 226-241.

J. Suh, A. Orinstein, M. Barton, C. M. Chen, I. M. Eigsti, N. Ramirez-Esparza, and D. Fein. 2016. Ratings of broader autism phenotype and personality traits in optimal outcomes from autism. fournal of Autism and Developmental Disorders 46, 11 (2016), 3505-3518.

A. Tartaro and J. Cassell. 2008. Playing with virtual peers: Bootstrapping contingent discourse in children with autism. In Proceedings of the International Conference on the Learning Sciences (ICLA'08). ACM, 382-389.

Report US National Research Council. 2002. Scientific Research in Education. Technical Report. US National Research Council.

S. Wass and K. Porayska-Pomsta. 2014. The uses of cognitive training technologies in the treatment of autism spectrum disorders. Autism: International fournal of Research and Practice. 18, 8 (2014), 851-871.

C. Whalen and L. Schreibman. 2003. Joint attention training for children with autism using behavior modification procedures. Journal of Child Psychology and Psychiatry 44, 3 (2003), 456-468.

M. Wooldridge and N. R. Jennings. 1995. Intelligent agents: Theory and practice. Knowledge Engineering Review 10, 2 (1995), 115-152.

B. Woolf. 2008. Building Intelligent Tutoring Systems. Morgan Kaufman.

Received July 2017; revised August 2018; accepted August 2018 